\title{
Antimicrobial resistance among GLASS pathogens in conflict and non-conflict affected settings in the Middle East: a systematic review
}

\author{
Claudia Truppa ${ }^{1,2^{*}}$ (D) and Mahmoud N. Abo-Shehada ${ }^{2}$
}

\begin{abstract}
Background: In spite of the evident general negative effects of armed conflict on countries' health systems and populations' health outcomes, little is known about similar impacts of conflicts on the spread of antimicrobial resistances (AMR). This review was to address this evidence gap and describe:

1. Patterns of AMR in the Middle East (ME) and resistance profiles of pathogens included in the Global AMR Surveillance System (GLASS) supported by the World Health Organization;

2. Differences in proportions of AMR isolates between conflict and non-conflict countries.
\end{abstract}

Methods: A systematic literature review was conducted following PRISMA guidelines and searching five electronic databases. Subject heading and free text were searched for "antimicrobial resistances" and "Middle East", to identify observational studies on AMR published from January 2011 to June 2018. Data were extracted from included articles on a predefined set of variables. Percentages of AMR were analysed as median and interquartile ranges. Risk of bias was assessed using the Newcastle-Ottawa Scale.

Results: A total of 132 articles met the inclusion criteria. Included studies showed heterogeneity in study design, laboratory methods and standards for interpretation of results, and an overall high risk of bias. Main findings were the following:

1. High proportions of carbapenem resistance in Acinetobacter spp. (median 74.2\%), and both carbapenem resistance (median 8.1 and 15.4\% for E. coli and K. pneumoniae respectively) and ESBL-production (median 32.3 and $27.9 \%$ for E. coli and K. pneumoniae respectively) amongst Enterobacteriaceae. S. aureus isolates showed a median methicillin resistance percentage of $45.1 \%$, while vancomycin resistance was almost absent. A median of $50 \%$ of the strains of S. pneumoniae showed non-susceptibility to penicillin.

2. Similar trends were observed in conflict and non-conflict affected countries.

(Continued on next page)

\footnotetext{
* Correspondence: ctruppa@icrc.org

'International Committee of the Red Cross, Geneva, Switzerland

${ }^{2}$ Faculty of Epidemiology and Population Health, London School of Hygiene and Tropical Medicine, University of London, London, UK
}

(c) The Author(s). 2020 Open Access This article is licensed under a Creative Commons Attribution 4.0 International License, which permits use, sharing, adaptation, distribution and reproduction in any medium or format, as long as you give appropriate credit to the original author(s) and the source, provide a link to the Creative Commons licence, and indicate if changes were made. The images or other third party material in this article are included in the article's Creative Commons licence, unless indicated otherwise in a credit line to the material. If material is not included in the article's Creative Commons licence and your intended use is not permitted by statutory regulation or exceeds the permitted use, you will need to obtain permission directly from the copyright holder. To view a copy of this licence, visit http://creativecommons.org/licenses/by/4.0/ The Creative Commons Public Domain Dedication waiver (http://creativecommons.org/publicdomain/zero/1.0/) applies to the data made available in this article, unless otherwise stated in a credit line to the data. 
(Continued from previous page)

Conclusions: There is a lack of standardization in the methodological approach to AMR research in the Middle East.

The proportion of antibiotic resistances among specific GLASS pathogens is high, particularly among Acinetobacter spp.

Keywords: Antibiotic resistance, Antimicrobial resistance, Middle East, Conflict

\section{Background}

Antimicrobial resistance (AMR), and more specifically antibiotic resistance (ABR), have become in the past two decades a globally rising concern. Since 2001, the World Health Organization (WHO) called for joining efforts in addressing the growing threat of AMR [1], following the pioneer example of the Pan-American Health Organization in establishing a surveillance network at regional level [2]. However, it was not until 2009-2010 that other regional action plans and surveillance systems were put in place, with such actions taking place initially in high income countries [3, 4].

In 2014, the World Health Assembly (WHA) issued resolution WHA67.25, calling for the development of a global action plan against AMR [5]. WHO took the lead of such process, publishing in 2015 a Global Action Plan on AMR [6], and establishing the Global AMR Surveillance System (GLASS) in order to ensure evidence base and integrated data collection and surveillance across countries [7].

The global call against AMR has found echo in many regions since then, with the progressive establishment of harmonized surveillance systems in Eastern Europe and Central Asia [8], and thourough situation analysis conducted in the South East Asia WHO Region [9].

Critically, many Low and Middle-Income Countries, particularly in Africa and the Middle East, have not yet fully established similar regional networks. Recently, systematic reviews on AMR have been conducted in the West Pacific Region [10] and in Africa, showing high prevalence of resistances to the most commonly used antibiotics, and highlighting the critical evidence gap from many countries of the African Region [11-13]. No similar attempts to collate evidence available in the Middle East have been performed so far. Recent studies conducted in high income countries on AMR in refugees, including refugees from the Middle East, have led to hypothesize an association between refugee status and risk of AMR transmission. However, such studies have failed to provide any evidence on whether the AMR was acquired in the home country, during the journey or in the host countries $[14,15]$.

The lack of evidence on the magnitude of AMR in the Middle East is not surprising, considering the wellknown health effects of the peculiar geopolitical dynamics of this area of the world: in fact the Middle East has witnessed over the past decades a sustained social and political turmoil, with more than half of the countries members of the Arab League being theatres of protracted armed conflict [16]. Since 2011 the situation has further escalated, with the Arab Spring and the conflicts in Syria, Yemen, and Mosul in Iraq [17].

Middle Eastern health systems in countries witnessing protracted armed conflict or carrying the burden of populations fleeing from them, have been progressively weakened, have seen their basic services disrupted, their health infrastructures damaged or destroyed, and a substantial proportion of their workforce either fleeing or being killed $[18,19]$. Armed conflicts have been already shown to have, in virtue of the above mentioned effects on the health system, a tremendous impact on the health outcomes of the populations affected, in terms of increased morbidity, mortality and disability [20-24].

Armed conflict and political instability in the Middle East constitute obstacles for the implementation of health policies and global action plans, including those related to proper AMR surveillance and stewardship. However, despite the fact that emergence of drug resistance has already been described as one of the potential effects of armed conflict since over more than one decade [25], no formal and systematized evidence has been gathered so far. Sporadic evidence has recently highlighted that victims of armed conflict might be at higher risk of harbouring and/or being infected by multidrug resistant (MDR) bacteria [26, 27], but overall AMR in the Middle East remains poorly documented, and no study conducted so far has ever attempted exploring the magnitude of the problem of AMR in conflict-affected settings in the region.

There are multiple pathways through which armed conflict can contribute to the creation and spread of AMR in the Middle East: disruption of healthcare systems; delayed access to healthcare; increased nosocomial transmission of resistant pathogens; increased community transmission of resistant pathogens in settings as refugee camps; poor antimicrobial stewardship in the countries affected and in humanitarian interventions; etc. [16, 20, 23, 28, 29].

This is the first review addressing explicitly the evidence gap on AMR in the Middle East, and the first one in attempting to explore specifically the hypothesized association between conflict and AMR.

\section{Methods}

The main objectives of this review are: 
1. To describe the patterns of AMR in the Middle East and the specific resistance profiles of pathogens listed in the WHO-supported GLASS; and

2. To identify any differences in AMR profiles in populations in conflict affected settings as compared to populations in non-conflict affected settings.

\section{Search strategy}

A systematic literature review was conducted following the Preferred Reporting Items for Systematic Reviews and Meta-Analysis (PRISMA) guidelines [30] (see Additional file 1: Appendix 1) and searching the following electronic databases: PubMed, MEDLINE, Embase, Global Health, CINAHL Plus, IMEMR (Index Medicus for the Eastern Mediterranean Region), Médecins Sans Frontières (MSF) and the International Committee of the Red Cross websites and the reference lists of the selected articles.

The search strategy included subject heading searches and free text searches for the following keywords: "antimicrobial resistances", "antibiotic resistances", "antimicrobial susceptibility" and, the name of countries in the review, in addition to all relevant synonyms. The detailed search strategy is reported in Additional file 1: Appendix 2.

A standard definition of "Middle East" is difficult to retrieve [31], and several sources include different countries under such title. Within the scope of this review, Middle East has been defined as the geopolitical area comprising all countries part of both the WHO Eastern Mediterranean Region (EMR) [32] and the World Bank Middle East and North Africa Region [33], and members of the League of Arab States [34], in order to include settings sharing the same language and whose political and social dynamics are strictly intertwined. As a result, eighteen countries are included in this study (Fig. 1).

Search items were imported in the reference manager software EndNote version X8.2. After removal of duplicates, screening of titles and abstracts was performed, and articles selected for full text screening were obtained. Full text was obtained either using the university library services or by directly contacting the author(s). Articles for which no access was obtained from university library services or if no reply was received within three weeks of the request to the author(s), were excluded from the review.

\section{Selection criteria}

Observational studies included in this review were cohort and cross-sectional studies describing the proportion, prevalence or incidence of AMR in Arab Middle Eastern civilian populations of both sexes and all ages (neonates: aged less than 28 days; infants: aged 28 days to 1 year; children: more than 1 year to 17 years of age; adults: aged 18 years or more), living in the abovenamed countries. Any other study, regardless of study design, which clearly specified the total number of isolates as denominator and the resistance profiles of individual pathogens, was also included, as suggested by Omulo et al. in a recent review on AMR research [13].

\section{Eligibility criteria}

Peer reviewed papers published since 2011 (beginning of the Arab Spring and the Syrian crisis) until mid-2018 in Arabic, English, French, Italian, Portuguese and Spanish

Fragile and conflict affected

Non-conflict affected

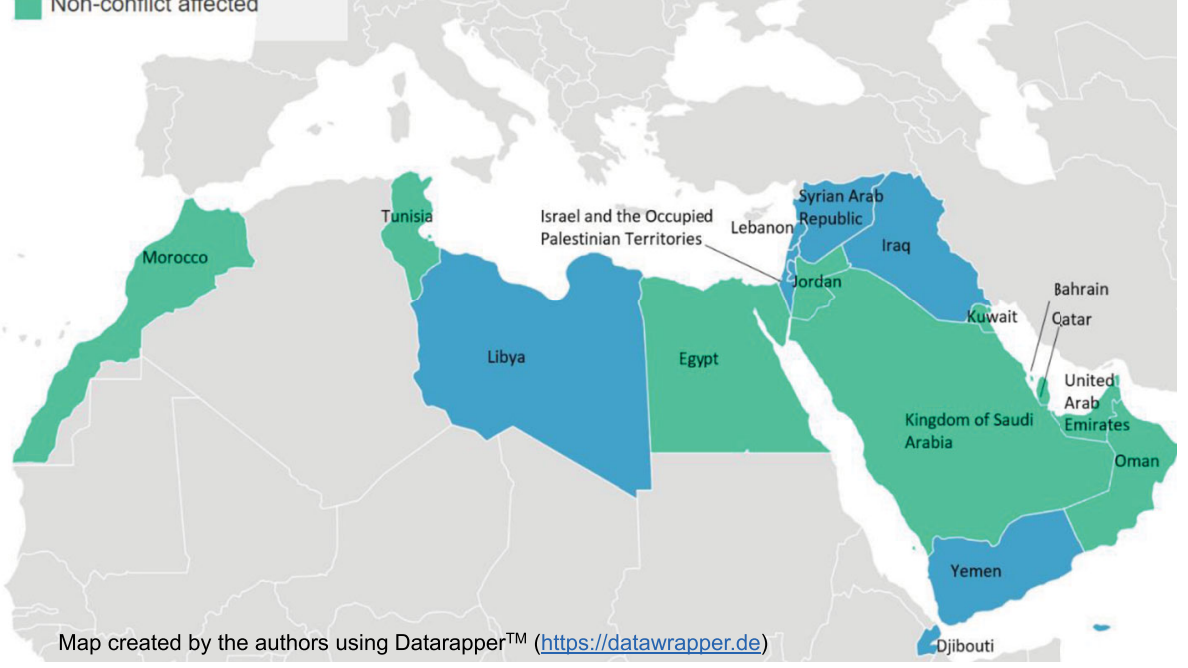

Fig. 1 Map of countries included in this systematic review on AMR and conflict in the Middle East (the identification as fragile and conflict affected and non-conflict affected is based on the World Bank classification, 2011-2018) 
were sought, on bacterial resistances in civilian populations living in the Middle East, reporting on data collected after the beginning of 2011 on AMR in the eight GLASS pathogens.

Papers dealing with non-Arab migrants in the Middle East, or military personnel deployed from non-Middle Eastern countries for combat operations in the Middle East, were excluded, considering that AMR carriage and/ or infection profiles of these populations could not be representative of the patterns of AMR in the area under study, as they could harbour AMR contracted in their home countries. Similarly, papers on AMR profiles in Arab Middle Eastern refugees in high income countries were excluded, as it would be impossible to ascertain whether the AMR profile was acquired in the home countries, during the migration journey, or in the host countries.

Exclusion criteria adopted were applied hierarchically in the following order: peer reviewed papers describing studies conducted outside the above defined geographical area of interest; reporting AMR data collected before 2011 or on AMR in other pathogens not included in GLASS; articles describing veterinary or environmental studies; studies on AMR patterns in military personnel deployed from non-Middle Eastern countries in the Middle East, or collected from non-Middle Eastern populations residing in any of the included countries; articles characterizing exclusively clusters of AMR bacteria and without information on the total of isolated microorganisms regardless of resistance profiles; intervention and analytical studies recruiting participants or specimens on the basis of a specific ABR profile; articles not available in full text in any of the above mentioned languages; correspondence, comments, case reports and case series.

\section{Types of exposures}

Countries were classified as "conflict-affected" if they were included in the World Bank list of "fragile and conflict-affected situations" [35]. According to the list, the following eight countries included in the review were defined as conflict-affected: Djibouti, Iraq, Israel and the Occupied Palestinian Territories (West Bank and Gaza), Lebanon, Libya, Syrian Arab Republic, and Yemen (Fig. 1), and the rest of studied countries were non-conflict affected.

\section{Types of outcome measures}

Primary outcome measures extracted were: incidence risk, prevalence, and proportion of AMR isolates.

\section{Data collection process}

A data extraction form was designed including: 1) Article information: first author, year of publication, year(s) of data collection, country in which the study was conducted, classification of the country as conflict-affected or nonconflict-affected; 2) Study information: type of study, study setting (community, primary care or hospital), study population, classification of the study population as conflict-affected or non-conflict-affected, sample size, age group(s), number of samples (or non-duplicate isolates, if available) collected, clinical syndrome(s) under study, primary outcome measure(s); 3) Microbiological information: pathogen(s) isolated, laboratory methodology employed for identification and antibiotic susceptibility testing (AST), criteria used for interpretation of resistances, AMR profile(s).

The data extraction form was designed based on the recommendations formulated by Omulo in her 2015 work [13], in order to promote comparisons of results across different low and middle income settings, as these were also adopted in a recent systematic review on AMR in Africa [11]. For the definition of the AMR profile, the total number of isolates included in the study was extracted, along with the number of non-susceptible isolates for all the antibiotics tested. The main AMR profiles were defined as those identified by WHO as "priority pathogens" for the public health significance they have; in the specific case of GLASS pathogens, these include: carbapenem-resistant Acinetobacter baumannii, carbapenem-resistant and Extended Spectrum Beta Lactamase (ESBL)-producing Enterobacteriaceae (E. coli and K. pneumoniae), third generation cephalosporin-resistant $N$. gonorrhoeae, methicillin-resistant and vancomycin-resistant S. aureus (MRSA and VRSA respectively), fluoroquinoloneresistant Salmonella spp. and Shigella spp., and penicillin non-susceptible S. pneumoniae [36].

For articles presenting data on multiple pathogens, data were collected exclusively on the resistance profiles of the GLASS pathogens. Where resistance profiles were indicated exclusively for MDR pathogens, data were extracted only on primary resistance profiles demonstrated in the initial total sample included in the study. Intermediate susceptibility, where reported, was consolidated with susceptibility, as per experts' recommendations at the time of writing, and formalized later in 2019 in the EUCAST guidance [37].

The data extraction form is detailed in Additional file 1: Appendix 3. Data were successively extracted in Microsoft Excel 2016 for analysis. A quantitative analysis was performed on 116 articles reporting on the above mentioned specific antibiotic resistances of public health significance, which consisted of the calculation of resistance median percentages and interquartile range (IQR).

Publication bias was assessed designing funnel plots for articles on one pathogen isolated from specific collection samples, where the number of studies was sufficient to allow the analysis, and performing Egger's regression test for statistical evidence of publication bias, using Stata ${ }^{\text {Tw }}$ software version 14.2. 


\section{Assessment of risk of bias}

An initial screening tool for overall quality appraisal was used. A subsequent in-depth assessment of risk of bias was performed adopting a modified version of the Newcastle-Ottawa Scale for cohort studies [38], and an adapted version to cross-sectional studies (both the screening tool and the modified scales are available in Additional file 1: Appendix 3), as it was recommended at the time of writing by the Cochrane Collaboration for the assessment of risk of bias in non-randomized studies [39].

The following categories were assessed: selection of participants or specimens, comparability of study groups, and outcome or exposure assessment according to the study type. Within each category, a variable number between two and three items was assessed, and colour coded according to the extent to which the study demonstrated a good (green), moderate, incomplete or doubtful (yellow), or poor (red) abidance to the epidemiological standards and good practices for the study design chosen.

Articles were classified as at high, moderate or low risk of bias according to the following criteria: a) High risk: poor epidemiological design in the three categories; b) Moderate risk: good epidemiological design in two categories or acceptable design in the three categories; and c) Low risk: good epidemiological design across all categories.

\section{Results}

\section{Study selection and characteristics}

A total of 13'166 records were identified; 4' 228 items in Embase, 2'223 in Medline, 3'541 in Global Health, 2' 603 items in PubMed, and 571 in CINAHL Plus and additional 71 records were identified, 68 items in IMEM $\mathrm{R}$ and 3 items in the MSF Field Research Website [40]. After removing duplicates, titles and abstracts of 6'684 records were screened, of which only 431 were eligible for full text screening. Of the 431 articles read in full text, 132 met the inclusion criteria (Fig. 2) and were included.

Table 1 describes the study characteristics. All the articles selected for inclusion in the study were in English except one study that was in French [100]. More than half of included studies were conducted in only three countries: Egypt (26.5\%), KSA (18.9\%), and Iraq (18.2\%). In all the other countries included in the review only between one and less than ten articles were included, and two countries, Djibouti and Qatar, had no included article.

A higher proportion (61.4\%) of articles were from stable countries and 51 articles, described AMR in fragile and conflict-affected countries: almost half of these were published in Iraq (Table 1).

Out of the 132 articles, 107 did not specify the nationality of the individuals from which the specimens were obtained. No assumption was made that a study conducted in one country would describe exclusively the population native of the same country, in virtue of the intense migration patterns from outside and within the Middle East $[173,174]$.

The vast majority of studies included were conducted in hospital and hospital laboratory settings (50.0 and $41.7 \%$ respectively). Community and primary health care settings where largely underrepresented (5.3\%). Inpatients constituted the source of half of the data (50.0\%) compared to outpatients. The source of microbiological data was not specified in $21.2 \%$ of studies.

Similarly, almost half (48.5\%) of the included articles did not specify the age groups and/or genders included in the study population. When specified, adults were the most commonly studied population $(33.3 \%$ of the included papers), followed by children (25.0\%). No studies from conflict-affected settings, however, presented data on children. Only one paper reported results from a study population entirely represented by men [48].

Only five articles were investigating AMR in immunosuppressed populations, represented either by HIVinfected patients [59], subjects who underwent liver transplantation [47], or patients affected by different types of malignancies [91, 115, 172]. Of these, only one was conducted in a conflict affected setting [59].

Only two articles presented ABR in diabetic patients $[42,61]$ : these were both from Egypt, and referred to skin and soft tissue infections.

\section{Appraisal of risk of bias}

The detailed summary of the assessment of risk of bias performed is available in Additional file 1: Appendix 3 and 4.

All studies included in this review were screened for the completeness of information provided including; the study design, research question and objectives, and description of the findings in terms of person, place and time, along with the justification of the sample size included and the provision of a measure of random variation of the presented results.

The study design was clearly stated in 29 out of the 132 articles included (Table 1). Although the study question was rarely focused in terms of population of interest, geographic area and time span of observation $(18.9 \%, 25 / 132)$, the study objectives were detailed in the majority of papers $(77.3 \%, 102 / 132)$. Time period of observation and geographical area of interest were clearly specified in $96.2 \%(127 / 132)$ of articles, while detailed demographic information on the study population, at least in terms of age groups and gender included, were available for $32.6 \%$ (43/132).

Only one study reported sample size calculation and employed representative population although not powered for the prevalence detected nor for the comparison 


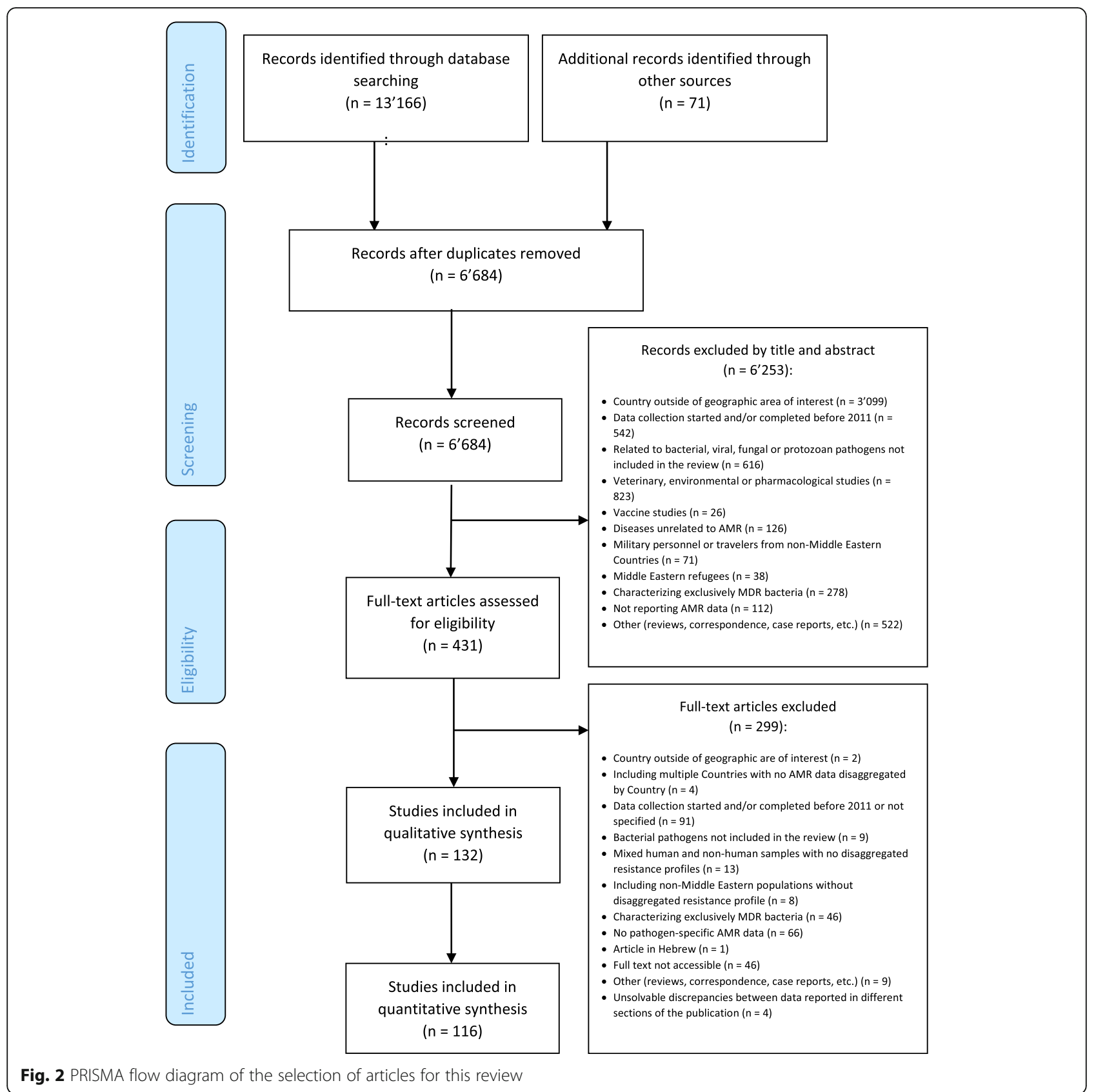

between the sub-groups performed [95]. Measures of sampling variation in the results were reported by only four studies [95, 161, 165, 168].

Statistical methods were in general poorly detailed, and mostly summarized in terms of descriptive statistics. Only three studies described the use of multivariate analysis - usually logistic regression - to control for confounding [45, 147, 168]. None of the studies took missing data into account in the analysis nor in the discussion, and similarly limitations and potential sources of bias were never mentioned in the discussion, with the exception of one surveillance study performed in Lebanon [123].

A substantial number of articles mentioned exclusively clinical suspicion from the attending physician as diagnostic criteria and rarely a clear case definition was detailed for the clinical syndrome under study. No clear sources for patient's socio-demographic data were descripted.

In general, cross-sectional studies presented major flaws in terms of sample selection, statistical methods employed (not described in the majority of cases), and 
Table 1 Summary of the characteristics of the 132 articles included in the systematic review on antimicrobial resistances among GLASS pathogens in conflict and non-conflict affected settings the Middle East

\begin{tabular}{|c|c|c|}
\hline Study characteristics & Number (\%) & References \\
\hline \multicolumn{3}{|l|}{ Year of publication } \\
\hline 2012 & $2(1.5)$ & {$[41,42]$} \\
\hline 2013 & $11(8.3)$ & [43-51] \\
\hline 2014 & $17(12.9)$ & {$[54-68]$} \\
\hline 2015 & $34(25.8)$ & [71-102] \\
\hline 2016 & $28(21.2)$ & [105-130] \\
\hline 2017 & $28(21.2)$ & [133-158] \\
\hline 2018 & $12(9.1)$ & {$[161-170]$} \\
\hline \multicolumn{3}{|l|}{ Year of completion of data collection } \\
\hline 2011 & $14(10.6)$ & {$[41,48,49,54,58,66,74,78,85,86]$} \\
\hline 2012 & $13(9.8)$ & {$[51,56,59,60,62,63,68,70,71,105,109]$} \\
\hline 2013 & $31(23.5)$ & $\begin{array}{l}{[46,47,50,55,61,64,67,69,72,73,75,80,81,87-89,91,92,94,99-101,113,120,123,} \\
127,132,145,153,155,159]\end{array}$ \\
\hline 2014 & $26(19.7)$ & $\begin{array}{l}{[57,65,76,79,83,84,90,93,95-98,104,114,116,124,125,129,130,135,149,154,157,} \\
158,160,167]\end{array}$ \\
\hline 2015 & $31(23.5)$ & $\begin{array}{l}{[77,82,102,103,106-108,110-112,115,117-119,121,122,126,128,131,134,136,140,} \\
142-144,147,148,150,151,166,171]\end{array}$ \\
\hline 2016 & $14(10.6)$ & {$[133,138,139,141,152,156,161,163-165,168-170,172]$} \\
\hline 2017 & $3(2.3)$ & {$[137,146,162]$} \\
\hline \multicolumn{3}{|l|}{ Country of publication } \\
\hline Non-conflict affected & $81(61.4)$ & \\
\hline Bahrain & $0(0)$ & NA \\
\hline Egypt & $35(26.5)$ & $\begin{array}{l}{[42,47,52,61,65,68,70-73,87,89,91,93,94,98,99,103,105,120,121,125,131,133,} \\
134,138,139,142,145,146,148,150,166,168,172]\end{array}$ \\
\hline Jordan & $8(6.1)$ & {$[49,57,88,119,132,161,163,169]$} \\
\hline Kingdom of Saudi Arabia (KSA) & $25(18.9)$ & $\begin{array}{l}{[41,46,51,62,69,76,77,80,81,83,85,90,92,102,107,108,111,115-117,135,136,154,} \\
164,170]\end{array}$ \\
\hline Kuwait & $1(0.8)$ & [130] \\
\hline Morocco & $7(5.3)$ & {$[63,64,86,100,143,153,155]$} \\
\hline Oman & $0(0)$ & NA \\
\hline Qatar & $0(0)$ & NA \\
\hline Tunisia & $1(0.8)$ & [152] \\
\hline United Arab Emirates (UAE) & $2(1.5)$ & {$[60,165]$} \\
\hline Multiple countries: Egypt and KSA & $2(1.5)$ & {$[74,97]$} \\
\hline Fragile and conflict affected & $50(37.9)$ & \\
\hline Djibouti & $0(0)$ & NA \\
\hline Iraq & $24(18.2)$ & $\begin{array}{l}{[53,56,58,67,78,79,82,84,95,96,109,110,112,114,118,126,129,137,140,151,156,} \\
158,162,171]\end{array}$ \\
\hline $\begin{array}{l}\text { Israel and the Occupied } \\
\text { Palestinian Territories }\end{array}$ & $7(5.3)$ & {$[43,44,50,54,113,144,147]$} \\
\hline Lebanon & $8(6.1)$ & {$[66,101,106,123,124,149,157,167]$} \\
\hline Libya & $6(4.5)$ & {$[48,59,75,104,159,160]$} \\
\hline Syrian Arab Republic & $4(3.0)$ & {$[45,55,128,141]$} \\
\hline Yemen & $1(0.8)$ & [122] \\
\hline Mixed conflict and non-conflict affected & $1(0.7)$ & \\
\hline Bahrain, Oman, UAE and Lebanon & $1(0.7)$ & [127] \\
\hline
\end{tabular}


Table 1 Summary of the characteristics of the 132 articles included in the systematic review on antimicrobial resistances among GLASS pathogens in conflict and non-conflict affected settings the Middle East (Continued)

\begin{tabular}{lll}
\hline Study characteristics & Number (\%) & References \\
\hline $\begin{array}{l}\text { Study design } \\
\text { Cross-sectional }\end{array}$ & $16(12.1)$ & {$[45,50,74,78,91,93,95,96,102,107,122,138,144,146,163,164]$} \\
Case-control & $2(1.5)$ & {$[57,165]$} \\
Cohort & $2(1.5)$ & {$[131,161]$} \\
Surveillance & $9(6.8)$ & {$[52,109,116,123,127,135,149,159,160]$} \\
Not specified & $103(78.1)$ & {$[41,42,46-49,51,53-56,58-73,75-77,80-90,92,94,97-101,103-106,108,110-115$,} \\
& & $117-121,124-126,128-130,132-134,136,137,139-143,145,147,148,150-158,162,166-$ \\
& &
\end{tabular}

Study setting

Hospital

$66(50.0)$

Laboratory

55 (41.7)

Primary care

$4(3.0)$

Community

Mixed

$3(2.3)$

$4(4.0)$

Source of data

Inpatients

$66(50.0)$

Outpatients

$12(9.1)$

Healthcare workers

$5(3.8)$

Students

Of which medical students

Mixed

4 (3.0)

$2(1.5)$

17 (12.9)

Not specified

$28(21.2)$

Age groups*

$\begin{array}{ll}\text { Neonates } & 6(4.5) \\ \text { Infants } & 15(11.4) \\ \text { Children } & 33(25.0) \\ \text { Adults } & 44(33.3)\end{array}$

All age groups

$13(9.8)$

Not specified

$58(43.9)$

Gender

$\begin{array}{ll}\text { Male } & 1(0.7) \\ \text { Female } & 0(0) \\ \text { Both } & 67(50.8)\end{array}$

Not specified
$[46,51-53,55,56,59,61,62,64,65,67,68,71,72,75-77,81-84,86,87,89-93,96,99-101$, $103,104,107-109,111,114,115,119,121,131-133,136,142,144,146-148,150,155-158$, $161,162,164,168,170,172]$

$[41,45,49,54,58,60,63,66,69,70,73,78-80,85,88,94,97,98,106,110,112,113,116-$ $118,120,123-129,134,135,137-141,143,145,149,151-154,159,160,165-167,169,171]$

$[50,74,122,130]$

$[95,102,163]$

$[43,44,57,105]$

$[41,42,46-48,51-56,60-63,65,68,69,71-73,82,83,85,86,89-92,96,99-101,103,104$, $106-111,115-118,121,124,126,131,133,134,136,138-140,147,150,151,153,156,159$, $161,162,167,168,172]$

$[50,57,59,74,77,84,97,114,122,130,132,155]$

$[81,87,144,148,170]$

$[44,95,102,163]$

$[102,163]$

$[43,45,66,70,75,76,105,119,137,141,145,146,154,164-166,169]$

$[49,58,64,67,78-80,88,93,94,98,112,113,120,123,125,127-129,135,142,143,149$, $152,157,158,160,171]$

$[55,71,92,119,133,156]$

$[55,64,86,93,101,103,108,109,114,119,127,132,145,146,156]$

$[50,55,62,64,67,77,79,84,86,90,93,95,100,101,103,107-109,114,115,122,127,132$, $136,139,145,146,153,155,156,159,169,172]$

(53, 56, 61, 62, 65, 76,81,84,86,87,89,90,95,99,101,102,107-109,111,114,115,130, $131,136,144,145,147,148,153,155,159,161-163,168-170,172]$

$[41,43,45,46,51,52,68,75,107,127,142,152,164]$

$[49,54,57-60,63,66,69,70,72-74,78,80,82,83,85,88,91,94,96-98,104-106,110,112$, $113,117,118,120,121,123-126,128,129,134,135,137,140,141,143,149-151,154,157$, $158,160,165-167,171]$

[48]

NA

$[41-44,49-53,61,62,65,66,71,74-77,81,86,88-90,95,98-102,107-109,111,114-116$, $119,122,127,130-133,136,141,142,145-148,152-157,160-165,168,169,172]$

$64(48.5) \quad[47,54-60,63,64,67-70,72,73,78-80,82-85,87,91-94,96,97,103-106,110,112,113$, $117,118,120,121,123-126,128,129,134,135,137-140,143,144,149-151,158,159,166$, $167,170,171]$ 
Table 1 Summary of the characteristics of the 132 articles included in the systematic review on antimicrobial resistances among GLASS pathogens in conflict and non-conflict affected settings the Middle East (Continued)

\begin{tabular}{|c|c|c|}
\hline Study characteristics & Number (\%) & References \\
\hline \multicolumn{3}{|l|}{ Clinical syndrome } \\
\hline Colonization & $21(15.9)$ & {$[41,44,50,51,57,74,77,81,83,87,92,93,95,102,111,119,132,144,148,163,170]$} \\
\hline Urinary tract infections & $20(15.2)$ & {$[45,49,54,59,75,84,100,107,109,114,130,146,147,154,155,159,164-166,169]$} \\
\hline Skin and soft tissue infections & $10(7.6)$ & {$[42,48,61,82,96,121,125,126,140,161]$} \\
\hline Of which war-related & $2(1.5)$ & {$[48,161]$} \\
\hline Bloodstream infections & $10(7.6)$ & {$[65,71,72,103,115,133,137,150,153,172]$} \\
\hline Respiratory tract infections & $6(4.5)$ & {$[62,64,89,99,122,162]$} \\
\hline Gastroenteritis & $5(3.8)$ & {$[58,67,79,98,149]$} \\
\hline Meningitis & $2(1.5)$ & {$[134,156]$} \\
\hline Keratitis & $1(0.7)$ & [142] \\
\hline Miscellanea & $43(32.6)$ & $\begin{array}{l}{[43,46,47,52,53,55,56,60,63,66,68-70,73,76,78,86,88,90,91,94,101,104,106,108,} \\
112,116-118,120,124,127,129,131,136,138,139,141,145,151,152,157,168]\end{array}$ \\
\hline \multicolumn{3}{|l|}{ Type of specimen } \\
\hline Urine & $20(15.2)$ & {$[45,49,54,59,75,84,100,107,109,114,130,146,147,154,155,159,164-166,169]$} \\
\hline Nasal/nasopharyngeal swab & $18(13.6)$ & {$[41,44,50,51,56,57,74,77,81,93,95,102,111,132,144,148,163,170]$} \\
\hline Blood & $10(7.6)$ & {$[65,71,72,103,115,133,137,150,153,172]$} \\
\hline Tissue swab/biopsy & $9(6.8)$ & {$[42,48,61,82,121,125,126,140,161]$} \\
\hline Faeces & $8(6.1)$ & {$[58,67,79,87,92,98,119,149]$} \\
\hline Sputum or other respiratory & $4(3.0)$ & {$[62,89,99,162]$} \\
\hline Other & $7(5.3)$ & {$[64,83,104,122,134,142,156]$} \\
\hline Miscellanea & $52(39.4)$ & $\begin{array}{l}{[43,46,47,52,53,55,60,63,66,68-70,73,76,78,86,88,90,91,94,97,101,105,106,108,} \\
110,112,113,116-118,120,123,124,127-129,131,135,136,138,139,141,143,145,151, \\
152,157,158,167,168,171]\end{array}$ \\
\hline Not specified & $4(3.0)$ & {$[80,85,96,160]$} \\
\hline \multicolumn{3}{|l|}{ Laboratory methods } \\
\hline \multicolumn{3}{|l|}{ Identification of microorganism } \\
\hline Morphology & $53(40.2)$ & $\begin{array}{l}{[41-44,47,48,50,51,54-58,61-63,66,67,73,74,78,79,81,87,91,93-96,99,100,102,105,} \\
109,111,113,114,119,122,125,127-129,132,136,142,144,146,148,150,152,156,169]\end{array}$ \\
\hline VITEK ${ }^{T M}$ & $21(15.9)$ & {$[46,72,75,76,80,82-85,88,101,106,108,117,118,140,151,154,158,162,171]$} \\
\hline API & $15(11.4)$ & {$[45,59,68,70,86,90,124,131,143,145,149,153,155,157,167]$} \\
\hline Others & $12(9.1)$ & {$[69,77,104,107,115,116,130,133,159,160,164,170]$} \\
\hline Multiple & $25(17.4)$ & $\begin{array}{l}{[53,60,64,65,92,97,98,103,110,112,120,121,123,126,135,137-139,147,161,163,} \\
165,166,168,172]\end{array}$ \\
\hline Not specified & $6(4.5)$ & {$[49,52,71,89,134,141]$} \\
\hline \multicolumn{3}{|l|}{ Antibiotic susceptibility testing } \\
\hline Disk diffusion & $64(48.5)$ & $\begin{array}{l}{[42,43,47-52,54,57-59,64,65,67,68,70,71,74,76,79,81,82,86,87,91,94,96,98-100,} \\
105,106,109,110,112,113,119-121,124-126,128,130,136,137,141-146,148,149,152, \\
153,155,156,162,166,169]\end{array}$ \\
\hline VITEK $^{T M}$ & $12(9.1)$ & {$[83,88,92,108,117,118,135,151,154,158,168,171]$} \\
\hline PCR & $7(5.3)$ & {$[55,62,66,78,101,102,129]$} \\
\hline E-test $^{T^{T M}}$ & $4(3.0)$ & {$[97,127,131,160]$} \\
\hline MIC & $4(3.0)$ & {$[46,53,90,134]$} \\
\hline Others & $3(2.3)$ & {$[77,104,115]$} \\
\hline Multiple & $35(26.5)$ & $\begin{array}{l}{[41,56,60,61,63,69,72,73,75,80,84,85,93,95,103,107,111,114,116,123,132,138-} \\
140,147,150,157,159,161,163-165,167,170,172]\end{array}$ \\
\hline Not specified & $3(2.3)$ & {$[89,122,133]$} \\
\hline
\end{tabular}


Table 1 Summary of the characteristics of the 132 articles included in the systematic review on antimicrobial resistances among GLASS pathogens in conflict and non-conflict affected settings the Middle East (Continued)

\begin{tabular}{lll}
\hline Study characteristics & Number (\%) & References \\
\hline Standard for interpretation of results & & \\
CLSI & $103(78.0)$ & $\begin{array}{l}{[41-46,50-52,54-57,59-61,63-67,69-71,74-76,79-82,84,86,88,90-92,94-96,98-100,} \\
102,103,105-121,124-126,130,132-134,136-150,155-159,161-169,172]\end{array}$ \\
& $3(2.3)$ & {$[85,97,122]$} \\
BSAC & $2(1.5)$ & {$[72,160]$} \\
EUCAST & $2(1.5)$ & {$[152,153]$} \\
CA-SFM & $4(3.0)$ & {$[53,68,124,127]$} \\
Multiple methods & $18(13.6)$ & {$[49,58,62,73,77,78,87,89,101,104,128,129,131,135,151,154,170,171]$} \\
Not specified &
\end{tabular}

* Articles can report data on more than one age group, and therefore the sum of all age groups can differ from the total number of articles GLASS Global Antimicrobial Resistance Surveillance System

NA Not Applicable

API Analytical Profile Index

$P C R$ Polymerase Chain Reaction

MIC Minimum inhibitory concentration

CLSI Clinical \& Laboratory Standards Institute

$B S A C$ British Society for Antimicrobial Chemotherapy

EUCAST European Committee on Antimicrobial Susceptibility Testing

CA-SFM Comité de l'Antibiogramme de la Societé Française de Microbiologie

possibility of misclassification of both exposures and outcome under study.

The cohort studies included in the review [52, 131, 161] showed overall lower risk of bias compared to other study designs. Two out of the three studies [52, 131] lacked detailed description of the statistical methods employed, in particular if and how control for confounding was performed and how losses to follow up were dealt with. Remarkably, one of the cohort studies included was conducted in a non-conflict affected country, but describing findings on a conflict-affected population, as it investigated AMR in war wounded civilian Syrian patients admitted to a Jordanian hospital [161].

The two case-control studies included [57, 165] poorly described the inclusion criteria for the cases and did not clearly detail the recruitment of controls. Data extracted from these two studies were not included in the quantitative analysis.

\section{Synthesis of results}

Patterns of ABR in the Middle East and differences between conflict-affected and non-conflict-affected countries.

The most commonly described pathogens were, in order of frequency, E. coli (40.9\% of the included studies, 54/132), S. aureus (34.1\%, 45/132), Acinetobacter spp. (29.5\%, 39/132), and K. pneumoniae $(25.8 \%, 34 / 132)$, both in conflict and non-conflict affected settings. Other bacteria were less represented in this review, and no study investigated AMR in N. gonorrhoeae.

Antibiotic susceptibility testing (AST) was performed for a total of 73 different antibiotics, with substantial inhomogeneity across studies for each pathogen. Due to the substantial heterogeneity of methodologies adopted, it was not possible to perform a meta-analysis as quantitative synthesis of the results from the standpoint of AMR profile of the studied pathogens: such heterogeneity was due to the differences in terms of study settings, study populations included in the studies, laboratory methodologies employed to appraise susceptibility to the different antibiotics, and clinical conditions investigated. In addition to this substantial variability, there was a significant proportion of studies with missing information on the above mentioned categories, along with an overall high risk of selection bias, misclassification of the exposure categories, and lack of control for confounding. However, in Table 2 median percentages and IQR of specific AMR profiles are reported for selected GLASS pathogens, focusing on the most frequently reported ones.

A third (32.3\%) of E. coli isolates showed ESBLproducing profile, and $8.1 \%$ resistance to carbapenems (IQR 0.6-25.3). In both cases, the proportion of resistant isolates appeared to be higher in non-conflict affected countries compared to conflict-affected ones.

Regarding S. aureus, the overall median percentage of methicillin-resistance was 45.1\% (IQR 26.0-61.6). Unfortunately, the number of articles was too small in conflict affected compared to non-conflict affected countries to make a reliable comparison, and again study populations were very heterogeneous $[44,95,144]$. However, from the few studies included, no major difference was detected between the two contexts.

Proportion of carbapenem resistance among Acinetobacter spp. isolates was significant (74.2\%) and appeared slightly higher in conflict-affected settings compared to stable countries ( $78.0 \%$ vs $72.7 \%$, respectively).

Only a small proportion of samples of $K$. pneumoniae was tested for carbapenem resistance and ESBL- 


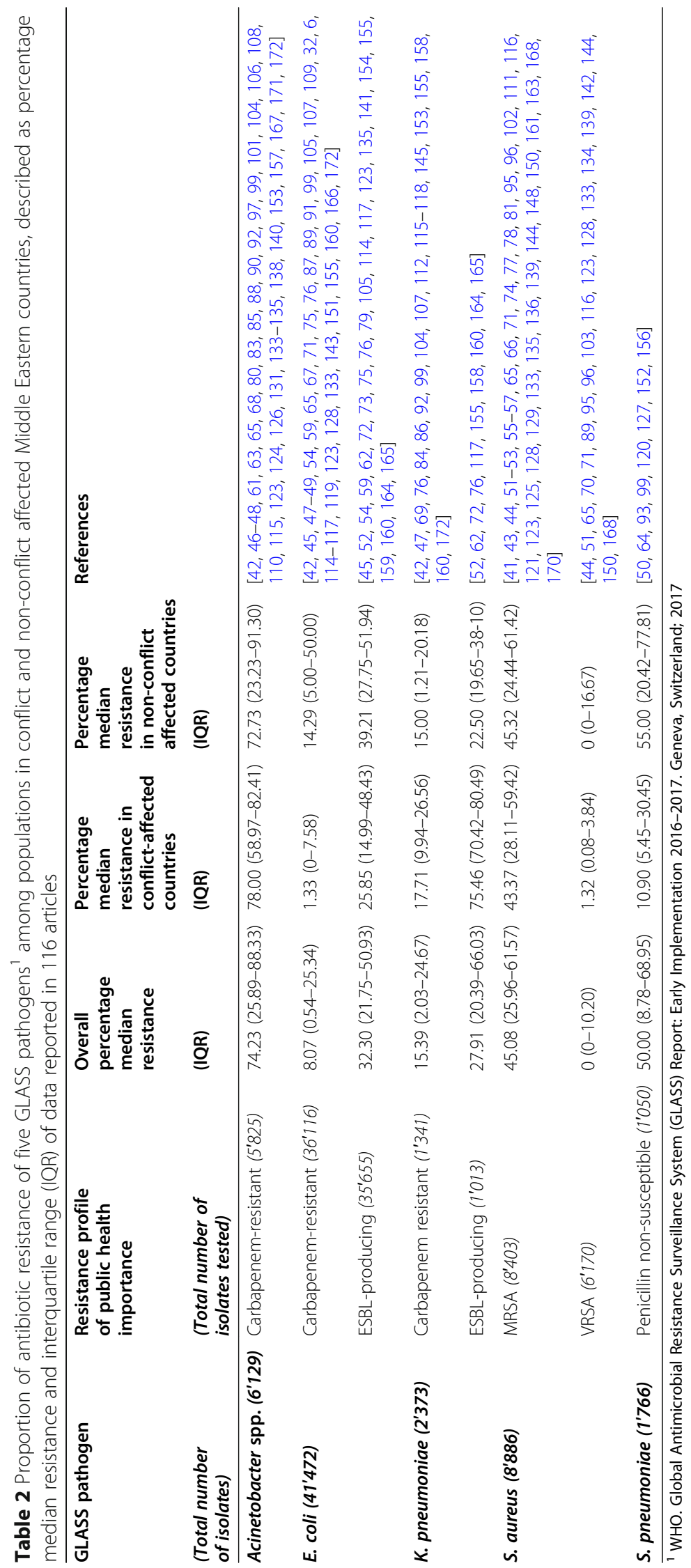


production (56.5 and $42.7 \%$ respectively) and $28.0 \%$ of samples appeared to be ESBL producers, with a substantial difference between conflict and non-conflict affected countries $(75.5 \%$ vs $22.5 \%$, respectively). The carbapenem resistance profile did not vary significantly between the two contexts, with an overall proportion of cases of $15.4 \%$.

As for S. pneumoniae, half of all isolates were detected as non-susceptible to penicillin, with substantially higher proportion in stable contexts $(55.0 \%)$ compared to conflict-affected settings (10.9\%).

Salmonella spp. and Shigella spp. AMR were investigated in too few studies (five and three respectively) to allow a valid summary to be included.

Tables 3 and 4 in the annex offer more details on the number of studies on each pathogen per country in conflict-affected vs non-conflict-affected countries, respectively. Tables 5 and 6 provide details on the number of studies per site of infections in conflict-affected vs non-conflict-affected countries, respectively. From these tables we can observe that studies conducted in nonconflict affected countries appeared to be slightly more focused in terms of site of infection under investigation compared to studies conducted in conflict affected countries, where in a substantial proportion of cases the site of infection was not specified, or the authors were analysing resistance profiles of bacteria isolated from a miscellanea of specimens.

Figure 3 presents the temporal trends in antibiotic resistances to the most commonly used classes of antibiotics for the four most frequently reported pathogens $(E$. coli, K. pneumoniae, Acinetobacter spp. and S. aureus), tracked by year of publication.

Publication bias was assessed for a sub-sample of ten studies which presented the proportion of ESBL producers among E. coli isolates on urinary samples, six of which were conducted in conflict-affected countries [45, 54, 59, $75,114,159]$ and four in non-conflict settings [154, 155, $164,165]$. Figure 4 shows the funnel plots elaborated on the logarithm of the proportion of ESBL producers amongst $E$. coli isolates in urine samples in all studies, and in studies conducted in conflict and non-conflict settings separately. The funnel plots show asymmetry and therefore would support the hypothesis of publication bias; however, Egger's regression test showed absence of statistical evidence of publication bias overall ( $p$-value 0.52 ), as well as specifically for studies conducted in non-conflict and conflict settings ( $p$-values 0.78 and 0.07 respectively).

\section{Discussion}

While it is undoubted that AMR constitutes one of the most dangerous threats to public health on a global scale, the scientific community has reached no consensus yet on how to estimate and quantify the burden of AMR $[175,176]$. This can be partly explained by the complex interactions between upstream and downstream determinants of AMR, which require a system level analysis through conceptual frameworks that need to be both context-specific and coherent at global level [177, 178].

In terms of upstream determinants, the Middle Eastern conflict-affected countries are low and middle income countries, while stable settings, particularly the Gulf Cooperation Council States, are high income economies [179]. These differences will influence the affordability to enforce measures, laws, and regulations regarding AMR. Beside the differences in wealth macro-indicators, common traits among the different countries emerge from the literature when investigating more proximal determinants of AMR, such as antibiotic prescription and self-medication practices [180, 181].

The interplay between the different determinants can be more pronouncedly hard to understand in fragile settings, particularly in situations of armed conflict, where additional drivers of AMR can complicate the picture. This has been insightfully analysed by Abbara and colleagues in a recent series of papers, in which it is described how the Syrian conflict has exacerbated the risk of AMR emergence and spread among the affected populations at a local level, and on a more global scene when considering the number of countries in which those fleeing are seeking refuge [182, 183].

\section{Summary of evidence}

Only six out of the 18 countries included in this systematic review have adhered to the GLASS (Bahrain, Egypt, Lebanon, Oman, KSA, and UAE) and are at different stages of the development or implementation of their National Action Plan on AMR, and amongst these only one - Lebanon - is considered a fragile context [184]. The substantial number of articles retrieved in this review denotes an active research on the topic in the region, both in conflict and non-conflict affected settings. However, the vast majority of evidence comes from only three countries: Egypt, KSA, and Iraq.

The 132 studies included in this review present heterogeneity and inconsistencies in terms of study designs, laboratory methodologies and standards adopted, and a variety of clinical scenarios included. The lack of harmonization in the regional surveillance system is not a prerogative of the Middle East, as it has been highlighted also in reviews conducted in other geographical areas outside the Western countries $[10,11,13]$.

The majority of the included articles were crosssectional studies, focusing on proportion and prevalence as outcome measures, with only two studies reporting incidence measures [131, 161]. Moreover, the sources of data being limited to hospitals and hospital laboratories, do not allow to describe the burden of AMR at 


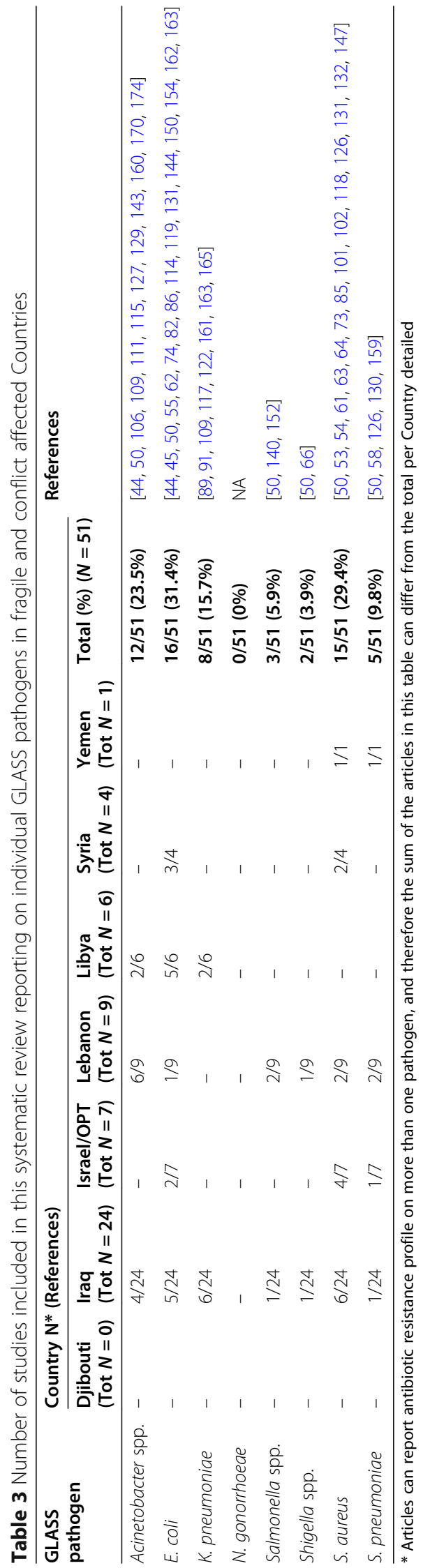




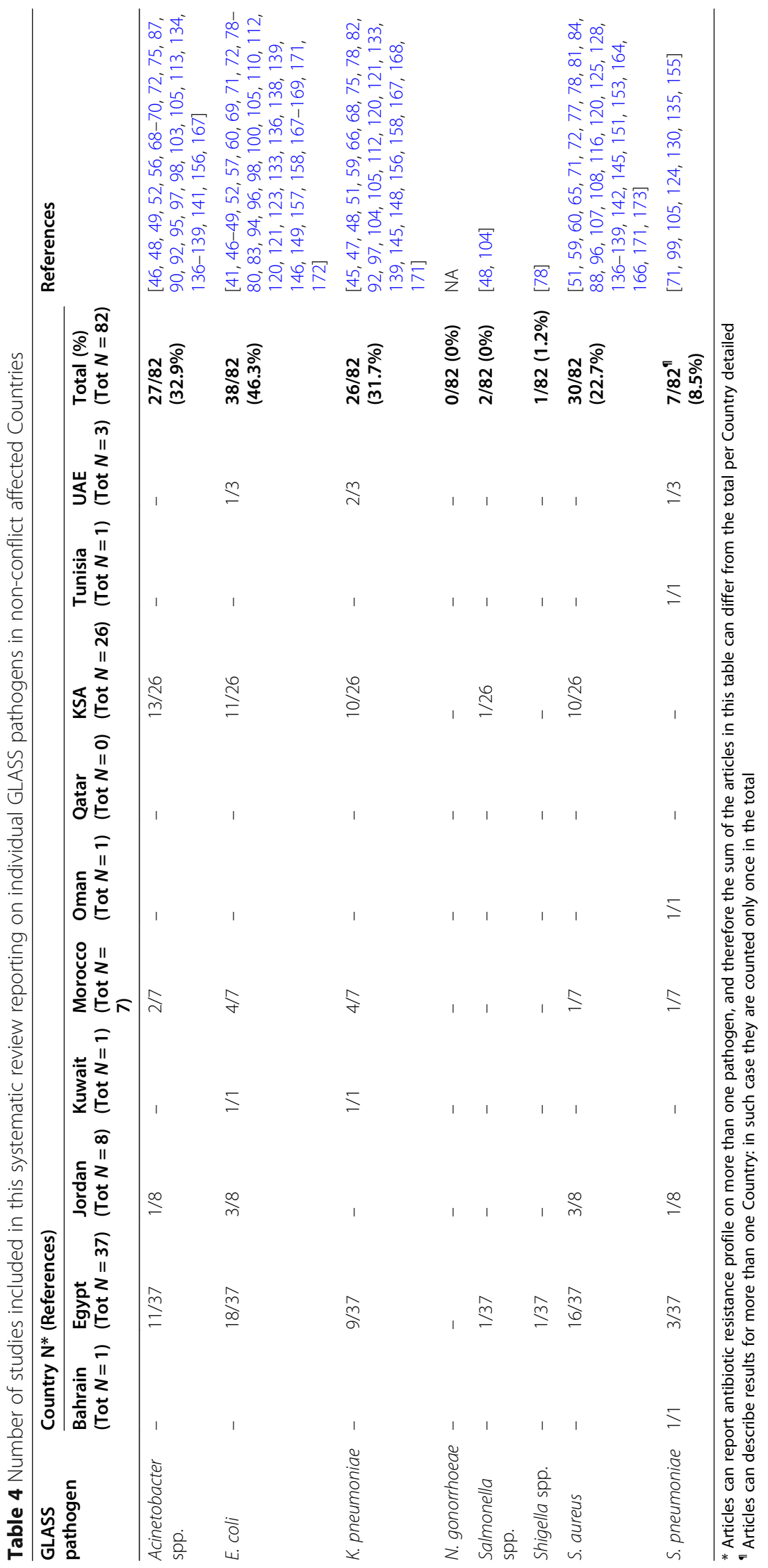




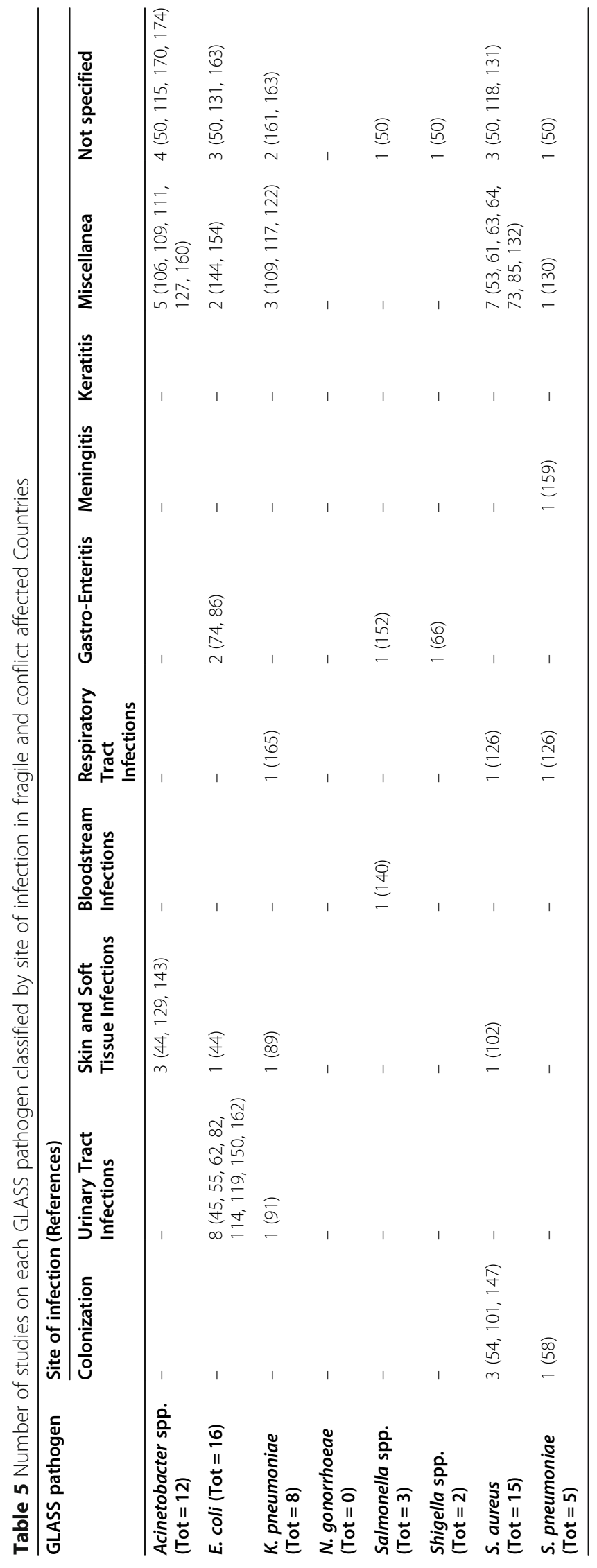




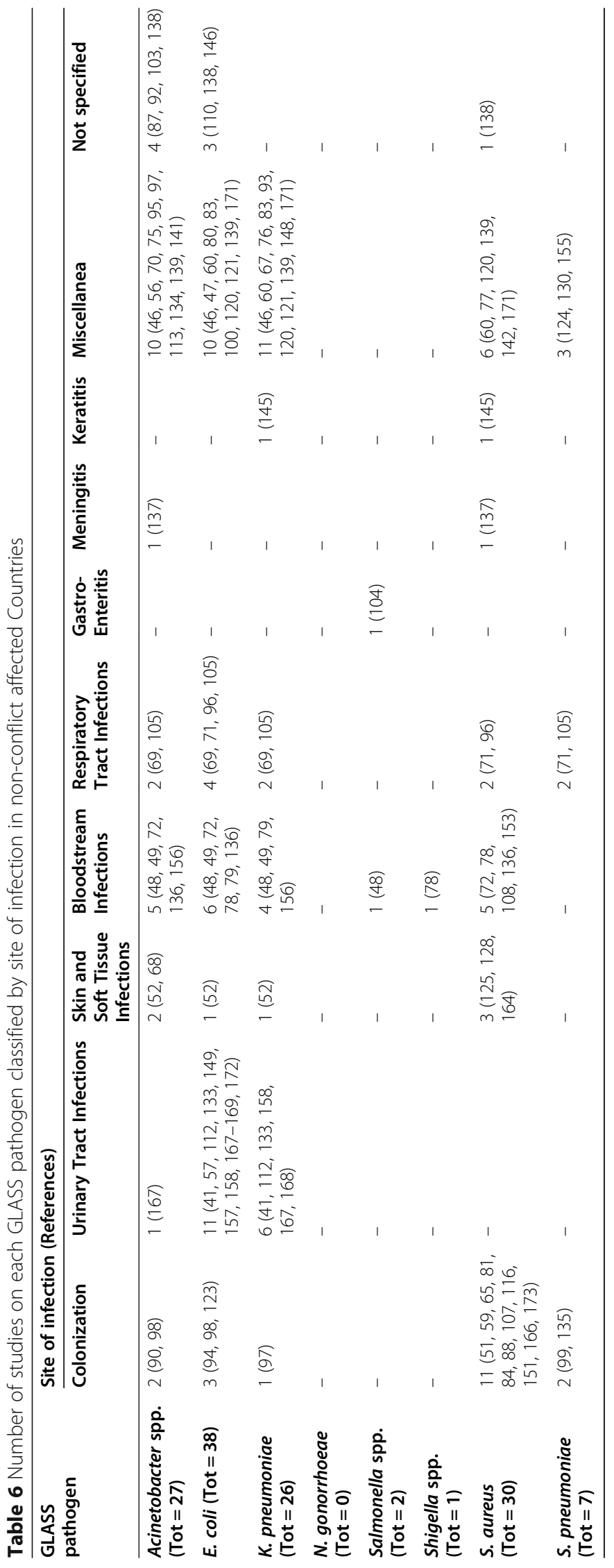


E. coli

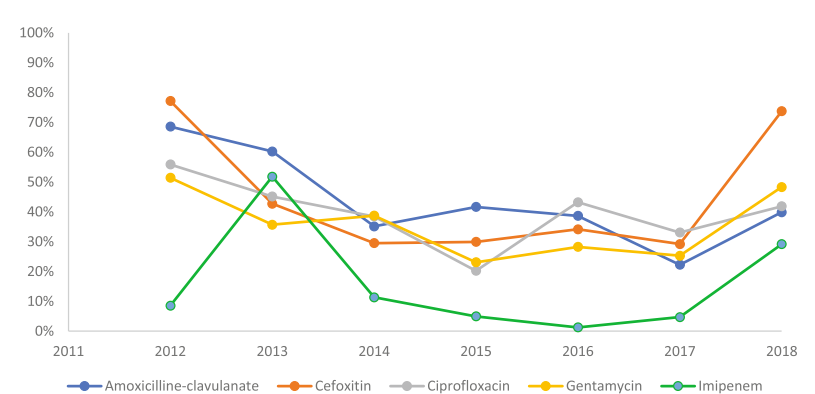

Acinetobacter spp

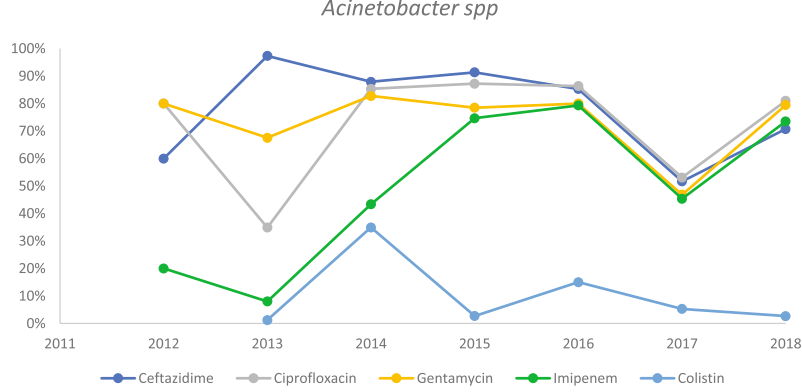

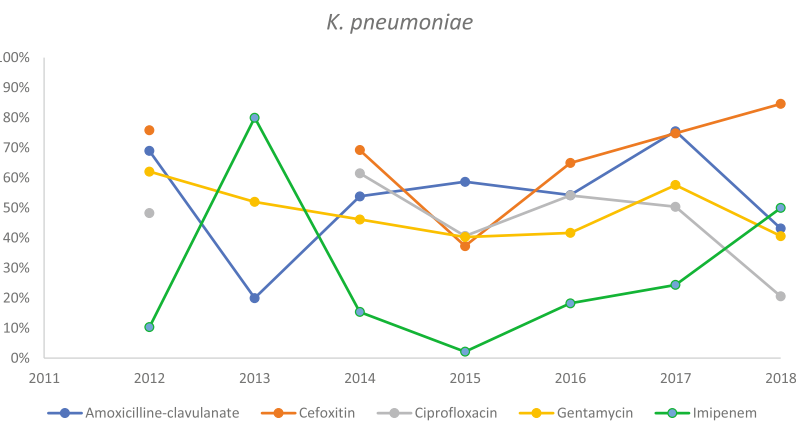

S. aureus

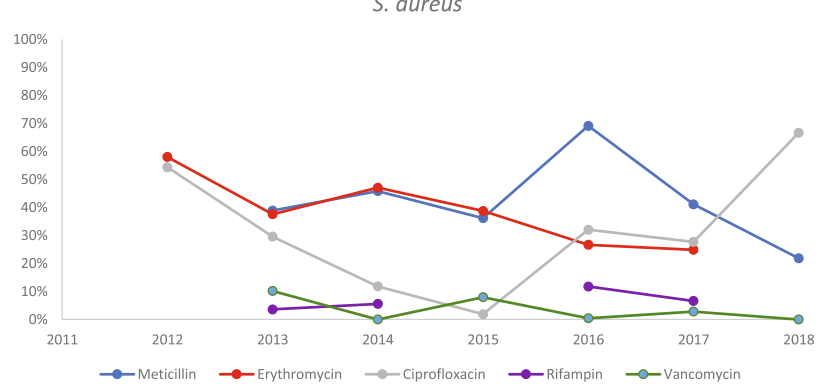

Fig. 3 Temporal trends in the proportion of resistance to five classes of antibiotics by year of publication among studies including E. coli, $K$. pneumoniae, Acinetobacter spp. and S. aureus

community and primary care level, where more than $80 \%$ of the total volume of antibiotics is used according to Western estimates [185], and where antibiotic prescription and consumption practices are less regulated than in hospital settings [186], particularly in the Middle East $[187,188]$.

The most frequently reported GLASS pathogens in the studies included in this review were those belonging to the Enterobacteriaceae family ( $E$. coli and $K$. pneumoniae), Acinetobacter spp., and $S$. aureus, both in conflict and non-conflict affected countries (see Tables 3 and 4).

Where possible, the resistance profiles identified were compared with those of the same micro-organisms reported in the European Antimicrobial Resistance Surveillance Network (EARS-Net) [189], particularly those from European Mediterranean countries, as this is geographically the closest example of consolidated and homogeneous data collection system on $\mathrm{ABR}$ to the Middle East.

The proportion of ABR emerging from the studies included in this review is concerning. In fact, among the Enterobacteriaceae included, around one third of the isolates showed an ESBL-producing profile. K. pneumoniae in conflict-affected countries appeared to have higher degrees of resistance to third generation cephalosporin, however random variation cannot be ruled out considering the limited number of studies conducted in these settings. The highest proportion of studies on both E. coli and K. pneumoniae were related to urinary tract infections, both in conflict and non-conflict affected countries (Tables 5 and 6). The carbapenem-resistance proportion among GLASS Enterobacteriaceae included in this review appear to be much higher than what is described in European settings and in the Mediterranean region $[189,190]$, however it is important to reiterate that the vast majority of studies included were hospital based, and investigating AMR in patients with underlying medical conditions, who are notoriously at higher risk of harbouring MDR strains.

The methicillin-resistance patterns in S. aureus detected in this review are similar to those described in a specific review on MRSA prevalence in the Middle East and North Africa [191], and the proportion of MRSA over the total number of $S$. aureus isolates appears to be higher than what described in other geographical regions such as Africa [192] and Europe, although again close to the figures of the European Mediterranean countries [189]. Among the articles reporting the AMR profile of $S$. aureus, nasal carriage was the most frequently studied condition (Tables 5 and 6).

The figures of carbapenem-resistance among Acinetobacter spp. are comparable with those of Southern Europe, particularly Spain, Italy and Greece, where the proportion vary between 69.9 and 94.9\% [189]. While three out of the 12 studies on Acinetobacter spp. in conflict affected countries were associated with skin and soft tissue infections, only two out of the 27 retrieved from non-conflict affected settings were investigating 
a

Funnel plot with pseudo $95 \%$ confidence limits

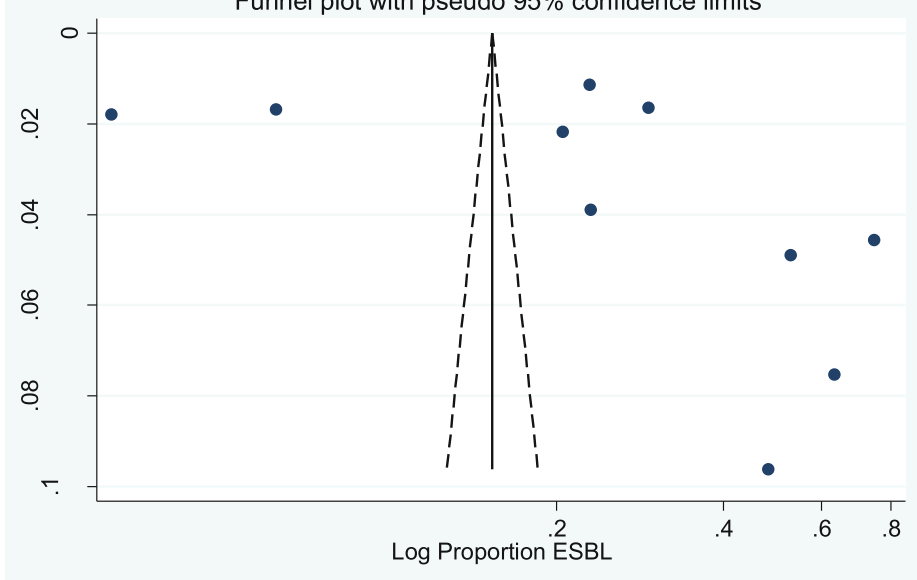

b

Funnel plot with pseudo $95 \%$ confidence limits

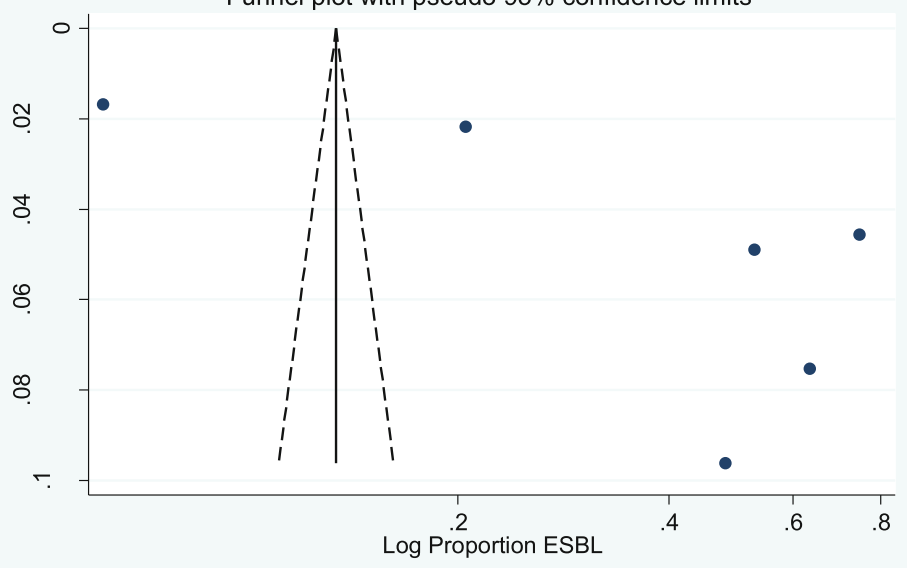

C

Funnel plot with pseudo $95 \%$ confidence limits

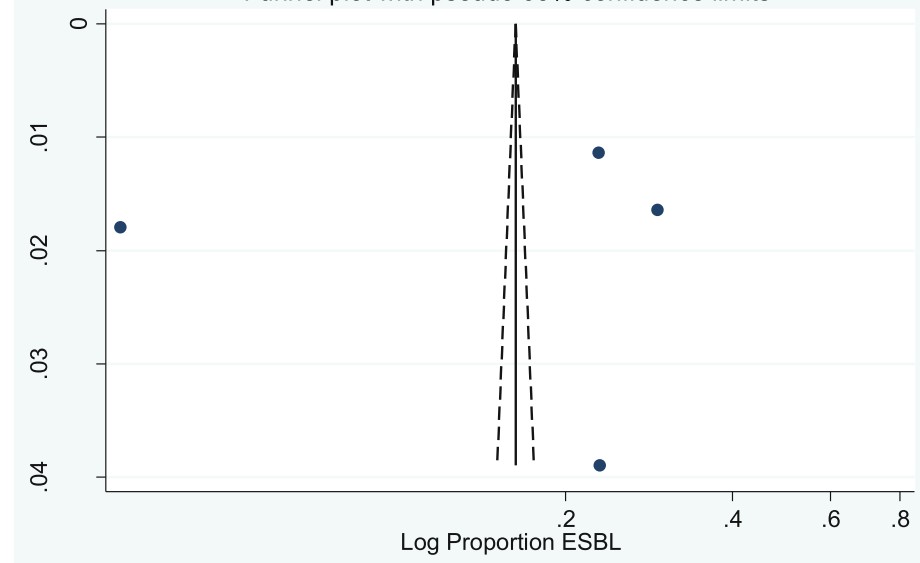

Fig. 4 Funnel plots for publication bias in ten studies reporting the proportion of ESBL producers among E. coli isolated from urinary samples: a) All studies (Eggers regression test $p=0.52$ ), b) Studies in conflict settings (Eggers regression test $p=0.78$ ), c) Studies in non-conflict settings (Eggers regression test $p=0.07$ ) 
this specific site of infection (see Tables 5 and 6). MDR Acinetobacter baumannii in particular has been described in the Middle East as associated with war-related wounds [26] already since the USA military interventions in Afghanistan and Iraq [193]. This has re-emerged recently in the literature related to wounded Syrian civilians since the onset of the Syrian crisis [194, 195], and confirmed also in the study by Rafei et al. included in this review [101], in which Syrian refugees admitted mostly for war-related wounds to a Lebanese hospital were significantly more likely $(p<0.001)$ to harbour carbapenem-resistant strains than Lebanese patients (74\% versus $47 \%)$. This peculiar feature, particularly in conflict-affected settings, deserves undoubtedly further investigation.

S. pneumoniae was less represented than other pathogens in this review, however a sufficient number of studies allowed to attempt a quantitative summary of the proportion of penicillin resistance observed: the findings of this review are consistent with those of other studies conducted in the region, and confirm that penicillin non-susceptibility among $S$. pneumoniae in the Middle East is frequently reported around 50\% [196].

No specific temporal trends were identified in the reports of antibiotic resistances to the most commonly used antibiotics among the four most frequently reported GLASS pathogens included in this systematic review (Fig. 3). However, caution must be applied when interpreting these results as no conclusive inference can be made on these data. In fact, the temporal trends were tracked exclusively by year of publication, and therefore might be relative to different years of sample collection: such detail was not consistently specified in the included papers, and where it was, it collated data on samples collected over several years, with the authors having no access to the raw data. Moreover, the studies included were heterogeneous in terms of sampling strategy, sample collection sites, laboratory methodology, and interpretation criteria adopted.

It is worth to underline the lack of research about $N$. gonorrhoeae in this region: this might be due to cultural and social aspects surrounding sexual and reproductive health knowledge, attitude, practices and taboos related to healthcare seeking for sexually transmitted infections (STIs) in the Middle East. The knowledge gap on STIs in this region is still significant, despite the recently describe increase in focus [197], and more research is needed to understand the prevalence of STIs and AMR related to them.

It is remarkable that a substantial proportion of studies were not investigating specific clinical conditions but were rather reporting unspecified or miscellaneous sites of infection (Tables 5 and 6): this is probably linked to the convenience sampling almost exclusively used in the research design of the included articles, and therefore to the poor methodological rigour of the evidence available from this geographical context.

\section{Specific considerations on conflict-affected settings}

With the currently available evidence it is not possible to draw definitive conclusions on whether the burden of AMR is differential between conflict and non-conflict affected settings in the Middle East, as different pathogens show conflicting results. The inconclusive findings of this review mirror those of similar studies conducted on AMR in M. tuberculosis among conflict-affected populations, which similarly failed to detect a significant difference in the levels of resistances to antimicrobials when comparing displaced populations to populations in the home countries [198].

Several elements can potentially explain the lack of differences detected between stable countries and conflict-affected countries in this review. First of all, studies from conflict-affected settings tend to be less precise in terms of completeness of information provided, and more focused on adult populations without severe comorbidities. Secondly, in conflict-affected settings the availability and accessibility of antibiotics could be severely compromised, thus minimizing the selective pressure on bacteria for the development of resistances. Thirdly, publication bias, although not statistically evident in this systematic review, might limit the availability of evidence from fragile contexts, due either to lack of access of researchers to the most at risk populations or to prioritization of research on most pressing public health needs and/or life-threatening conditions (such as war trauma or acute malnutrition). The visual evidence of publication bias that emerges from the funnel plots is contradicted by the results of the Egger's test. Caution must be applied when interpreting these results, as there are well described limitations with the use of funnel plots to assess publication bias in this type of systematic review [199]. Lastly, there might be less awareness, both among health authorities and humanitarian health organizations delivering health services in conflict-affected countries, of the potential public health threat that an unregulated and uncontrolled distribution of antibiotics might represent for the population.

In summary, the pathways through which conflict and non-conflict-affected countries can develop antibiotic resistances might differ based on the social, economic and political context. This stresses the importance of strengthening national and regional surveillance systems and adopting harmonized approaches that tackle antibiotic resistances at all levels, from agriculture and food safety to veterinary medicine, from legislative regulation to improved quality of scientific research, through a One Health approach as advocated by WHO. 


\section{Limitations}

This systematic review presents some limitations that need to be taken into account when interpreting the results described.

From a methodological perspective, only one author screened and selected the available literature applying inclusion and exclusion criteria: while this is not aligned with the best practices required to present a systematic review, it was due to the nature and the specific requirements of a project that started as an individual work within an academic path, and it was mitigated by an independent supervision by the second author in view of the peer review process.

From the perspective of completeness of data and qualitative analysis of the results, there was no data collection on clinical outcomes - such as mortality - which was a choice dictated by the fact that the available literature was mainly laboratory based and vastly lacking in this type of detail.

Another critical element missing from this review is the proportion of multi drug resistant microorganisms among those identified: this was not included by virtue of the lack of reporting and/or the lack of access to raw data from the included studies where reported.

The strict focus on GLASS bacteria might have led to overlook important pathogens, bacterial and nonbacterial, that might be relevant to the Middle Eastern context, such as Pseudomonas aeruginosa [200-202], Neisseria meningitidis [203], or viral infections - such as respiratory viruses - that are prevalent and of significant public health importance in this context [204].

From a standpoint of completeness and validity of the evidence retrieved, there are several elements that need to be mentioned as caveats before making any inference on the magnitude of the problem of AMR resistances in the Middle East. One element that needs to be mentioned is the fact that grey literature was not specifically searched for this review, and therefore some evidence might not be represented in the presented results. This was primarily due to the difficulties in retrieving unpublished reports particularly in conflict-affected settings. The main aspect to be cautiously appraised lies in the methodological weaknesses of the studies included in this review, including sampling. It is not possible in fact to rule out sampling variation as first possible explanation of the magnitude of proportions of AMR observed. The hospital-based cross-sectional study design dominating the published literature on the topic adds uncertainty to the validity and the generalizability of findings to the wider Middle Eastern population.

The limitations generated by these factors might be further impaired by the high risk of selection bias, information bias, misclassification, and the limited control for the potential confounding effect of socio-demographic variables detected in a considerable proportion of studies (Additional file 1: Appendix 4).

The strict inclusion and exclusion criteria applied, along with the descriptive analysis performed, that takes into account the variability observed and is methodologically aligned with that reported in similar studies in other contexts [11], are an attempt to both provide a reliable summary of the evidence available and make the findings interpretable and comparable from the perspective of scarce homogeneity and systematization of knowledge on the issue of AMR in resource limited settings.

The consistency of the findings described with those available in the literature on specific pathogens in the region leads to hypothesize that, despite the limitations above described, the concerning high proportion of AMR strains detected in this review has a certain degree of validity.

\section{Conclusions}

Based on the findings described in this systematic review, the first aspect that emerges is the clear lack of standardization in the methodological approach to AMR research in the Middle East, which hinders any possibility of drawing conclusions on the incidence or prevalence of specific resistance patterns at population level in the Middle East. This is mainly due to the predominantly hospital-based, cross-sectional nature of the studies performed, and is further aggravated by some methodological aspects: first of all, the convenience sampling almost universally adopted to investigate AMR, and secondly the lack of stratification or other statistical approaches to control for the multiple potential confounding effects that can play a role in the emergence and spread of AMR.

From what emerges from the descriptive analysis offered as a summary in this review, the proportion of antibiotic resistances among specific GLASS pathogens is concerning, particularly in the case of Acinetobacter spp., which deserves further investigation, particularly considering its predominance in war-related wounds.

However, it is not possible to draw any conclusion on the hypothesized differences in the magnitude of the problem of AMR between conflict and non-conflict affected countries, due to the flaws above described.

It is recommended that Middle Eastern country who have not done so yet, join the second phase of implementation of GLASS: to facilitate this, an Arabic version of both the GLASS website and GLASS manual will be needed.

The Middle Eastern scientific community should also adhere to the standardized methods promoted and supported by GLASS for AMR research and reporting, in order to improve the accuracy, quality and comparability of data collected on AMR in this region. Such harmonization effort 
will allow a more in-depth understanding of the drivers and patterns of acquisition and transmission of antibiotic resistances in the Middle East.

A stronger focus on population-based and primary care-based research will be needed, in order to avoid capturing exclusively high-risk populations in hospital settings, which could distort the findings. Such knowledge is necessary for improving national and local treatment guidelines, tailoring them to the specificities of each context.

Governments, academics, as well as aid agencies in conflict-affected countries, should try in parallel to promote research on and implementation of appropriate antibiotic resistance surveillance system and antibiotic stewardship programs at all levels of care, in order to timely tackle the threat of AMR through optimization of antibiotic prescription and consumption practices based on the resistance profiles circulating in this region.

\section{Supplementary Information}

Supplementary information accompanies this paper at https://doi.org/10. 1186/s12879-020-05503-8.

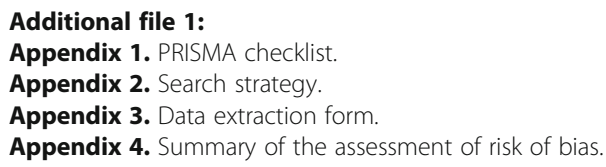

\section{Abbreviations}

ABR: Antibiotic resistance; AIDS: Acquired Immune Deficiency Syndrome: AMR: Antimicrobial resistance; API: Analytical Profile Index; AST: Antibiotic Susceptibility Testing; BSAC: British Society for Antimicrobial Chemotherapy; CA-SFM: Comité de I'Antibiogramme de la Societé Française de Microbiologie; CDC: Centre for Disease Prevention and Control; CLSI: Clinical and Laboratory Standards Institute; EARS-net: European Antibiotic Resistance Surveillance Network; ECDC: European Centre for Disease Control; EMR: Eastern Mediterranean Region; ESBL: Extended Spectrum Beta Lactamase; EUCAST: European Committee on Antimicrobial Susceptibility Testing; GLAS S: Global Antimicrobial Resistance Surveillance System; HIV: Human Immunodeficiency Virus; IMEMR: Index Medicus for the Eastern Mediterranean Region; IQR: Interquartile Range; KSA: Kingdom of Saudi Arabia; MDR: Multidrug Resistant; MIC: Minimum Inhibitory Concentration; MRSA: Methicillin-Resistant Staphylococcus aureus; MSF: Médecins sans Frontières; NCDs: Non-Communicable Diseases; PCR: Polymerase Chain Reaction; PRISMA: Preferred Reporting Items for Systematic Reviews and Meta-Analysis; STIs: Sexually Transmitted Infections; UAE: United Arab Emirates; VRSA: Vancomycin-Resistant Staphylococcus aureus; WHA: World Health Assembly; WHO: World Health Organization

\section{Acknowledgements}

The authors would like to thank Dr. Sophie Reshamwalla for thoroughly proof-reading of the manuscript and providing valuable comments.

\section{Authors' contributions}

$C T$ formulated the research questions, contributed to the definition of the search strategy, performed the first screening of titles and full texts reviews, read full the full texts of the selected articles to assess eligibility for inclusion, extracted the data from the articles, assessed the risk of bias for the included studies, analysed the results, and drafted all sections of the manuscript. MNAS contributed to the formulation of the research questions, revised the search strategy, the screening of titles and full texts, the data extraction from the selected articles, the assessment of risk of bias for the included studies, the analysis of results, and commented and edited all sections of the manuscript. Both Authors read and approved the final manuscript.

\section{Funding}

The study was not funded by any sponsor/donor and was entirely conducted by the authors.

\section{Availability of data and materials}

The data that support the findings of this study are available upon request to the corresponding author.

Ethics approval and consent to participate

Not applicable in virtue of the study design (systematic literature review).

\section{Consent for publication}

Not applicable in virtue of the study design (systematic literature review).

\section{Competing interests}

The authors declare that they have no competing interests.

Received: 11 February 2020 Accepted: 12 October 2020

Published online: 09 December 2020

\section{References}

1. WHO. WHO Global Strategy for Containment of Antimicrobial Resistance. Geneva, Switzerland; 2001.

2. ReLAVRA. Red Latinoamericana de Vigilancia de la Resistencia a los Antimicrobianos Buenos Aires, Argentina. 1996 [updated 2018. Available from: http://antimicrobianos.com.ar/category/resistencia/relavra/.

3. CDC. Antibiotic / Antimicrobial Resistance Atlanta, USA, 2010. [updated 19/ 07/2010. Available from: https://www.cdc.gov/drugresistance/actionplan/ surveillance1.html.

4. ECDC. Antimicrobial resistance surveillance in Europe Stockholm, Sweden: ECDC; 2010 [updated 24/11/2010. Available from: https://ecdc.europa.eu/en/ publications-data/antimicrobial-resistance-surveillance-europe-2009.

5. World Health Assembly. Antimicrobial resistance. World Health Assembly; 2014 24/05/2014

6. WHO. Global action Plan on Antimicrobial Resistance. Geneva, Switzerland: World Health Organization; 2015.

7. WHO. Global Antimicrobial Resistance Surveillance System (GLASS) Report: Early Implementation 2016-2017. Geneva, Switzerland; 2017.

8. WHO. Central Asian and Eatern European Surveillance System of Antimicrobial Resistance (CAESAR): Regional Office for Europe; 2015 [updated 2018. Available from: http://www.euro.who.int/en/health-topics/ disease-prevention/antimicrobial-resistance/about-amr/central-asian-andeastern-european-surveillance-of-antimicrobial-resistance-caesar.

9. WHO. Situation Analysis on Antimicrobial Resistance in the South-East Asia Region. Regional Office for South-East Asia; 2016.

10. Cowling BJ, Lim WW, Wong JYT, Fang VJ, Wu P. Antibiotic resistance in the Western Pacific region: a systematic review. Int J Infect Dis. 2016;53.

11. Tadesse BT, Ashley EA, Ongarello S, Havumaki J, Wijegoonewardena M, Gonzalez IJ, et al. Antimicrobial resistance in Africa: a systematic review. BMC Infect Dis. 2017;17(1):616

12. Ampaire L, Muhindo A, Orikiriza P, Mwanga-Amumpaire J, Bebell L, Boum Y. A review of antimicrobial resistance in East Africa. Afr J Lab Med. 2016;5(1):432

13. Omulo S, Thumbi SM, Njenga MK, Call DR. A review of 40 years of enteric antimicrobial resistance research in eastern Africa: what can be done better? Antimicrob Resist Infect Control. 2015:4(1):1.

14. de Smalen AW, Ghorab H, Abd El Ghany M, Hill-Cawthorne GA. Refugees and antimicrobial resistance: A systematic review. Travel Med Infect Dis. 2017;15:23-8.

15. Maltezou HC, Theodoridou M, Daikos GL. Antimicrobial resistance and the current refugee crisis. J Glob Antimicrob Resist. 2017:10:75-9.

16. Musani A, Shaikh IA. The humanitarian consequences and actions in the eastern Mediterranean region over the last 60 years--a health perspective. East Mediterr Health J. 2008;14(Suppl):S150-6.

17. The International Institute for Strategic Studies. Middle East. Armed Conflict Survey. 2017: Int Institut Strat Stud; 2017. p. 83-162.

18. ESCWA. Protracted conflict and development in the Arab region. New York, USA: United Nation; 2015. 
19. ICRC. Protracted Conflict and Humanitarian Action: some recent ICRC experiences. Geneva, Switzerland: The International Committee of the Red Cross; 2016 August 2016.

20. Ghobarah HA, Huth P, Russet B. Civil wars kill and maim people - long after the shooting stops. Am Political Sci Rev. 2003;97(2):189-202.

21. Hotez PJ. Modern Sunni-Shia conflicts and their neglected tropical diseases. PLoS Negl Trop Dis. 2018;12(2):e0006008.

22. Jasovsky D, Littmann J, Zorzet A, Cars O. Antimicrobial resistance-a threat to the world's sustainable development. Ups J Med Sci. 2016;121(3):159-64.

23. Mokdad AH, Forouzanfar MH, Daoud F, El Bcheraoui C, Moradi-Lakeh M, Khalil I, et al. Health in times of uncertainty in the eastern Mediterranean region, 1990-2013: a systematic analysis for the global burden of disease study 2013. Lancet Glob Health. 2016:4(10):e704-e13.

24. Global Burden of Disease, Collaborators EMR. Danger ahead: the burden of diseases, injuries, and risk factors in the Eastern Mediterranean Region, 1990-2015. Int J Public Health 2017.

25. Gayer M, Legros D, Formenty P, Connolly MA. Conflict and emerging infectious diseases. Emerg Infect Dis. 2007;13(11):1625-31.

26. Sahli ZT, Bizri AR, Abu-Sittah GS. Microbiology and risk factors associated with war-related wound infections in the Middle East. Epidemiol Infect. 2016:144(13):2848-57.

27. Teicher CL, Ronat JB, Fakhri RM, Basel M, Labar AS, Herard P, et al. Antimicrobial drug-resistant bacteria isolated from Syrian war-injured patients, august 2011-march 2013. Emerg Infect Dis. 2014;20(11):1949-51.

28. Iqbal Z. War and the health of nations. Stanford, California: Stanford University Press; 2010

29. Gates S, Hegre H, Nygård HM, Strand H. Development consequences of armed conflict. World Dev. 2012;40(9):1713-22.

30. Moher D, Liberati A, Tetzlaff J, Altman DG, Group P. Preferred reporting items for systematic reviews and meta-analyses: the PRISMA statement. PLoS Med. 2009;6(7):e1000097.

31. Özalp ON. Where is the Middle East? The definition and classification problem of the Middle East as a regional subsystem in international relations. Turk J Politics. 2011;2(2):5-21.

32. WHO. WHO Regional Office for the Eastern Mediterranean Region: Countries 2018 [Available from: http://www.emro.who.int/countries.html.

33. The World Bank. The World Bank: Middle East and North Africa 2018 [updated 2018. Available from: http://www.worldbank.org/en/region/mena.

34. League of Arab States. League of Arab States 2018 [Available from: http:// www.lasportal.org/ar/Pages/default.aspx.

35. The World Bank. The World Bank: Harmonized List of Fragile Situations 2018 [updated 24/05/2018. Available from: http://www.worldbank.org/en/topic/ fragilityconflictviolence/brief/harmonized-list-of-fragile-situations.

36. WHO. Global priority list of antibiotic-resistant bacteria to guide research, discovery, and development of new antibiotics 2017 [Available from: http:// www.who.int/news-room/detail/27-02-2017-who-publishes-list-of-bacteriafor-which-new-antibiotics-are-urgently-needed.

37. European Committee on Antimicrobial Susceptibility Testing EUCAST. New definitions of S, I and R from 2019. [Available from: https://www.eucast.org/ newsiandr/.

38. Wells G, Shea B, O'Connell D, Peterson J, Welch V, Losos M, et al. The Newcastle-Otawa Scale (NOS) for assessing the quality of nonrandomised studies in meta-analysis Ottawa, Ontario, Canada: The Ottawa Hospital Research Institute; 2013 [Available from: http://www.ohri.ca/programs/ clinical_epidemiology/oxford.asp.

39. Higgins J, Green S. Cochrane Handbook for Systematic Reviews of Interventions Version 5.1.0 2011 [updated March 2011. Available from: www. handbook.cochrane.org.

40. Médecins Sans Frontieres. MSF Field Research 2018 [Available from: http:// fieldresearch.msf.org/msf/.

41. Abdalla NM, Haimour WO, Osman AA, Hassan A. Assessment of the multifactorial effect on antimicrobial sensitivity in positive Staphylococcus aureus clinical isolates from Assir region, Saudi Arabia. J Med. 2012;13(2): 152-9.

42. Esmat MM, Al-Islam AS. Diabetic foot infection: bacteriological causes and antimicrobial therapy. J Am Sci. 2012:8(10):389-93.

43. Adwan G, Adwan K, Jarrar N, Salama Y, Barakat A. Prevalence of seg, seh and sei genes among clinical and nasal Staphylococcus aureus isolates in Palestine. Br Microbiol Res J. 2013;3(2):139-49.

44. Adwan K, Jarrar N, Abu-Hijleh A, Adwan G, Awwad E, Salameh Y. Molecular analysis and susceptibility patterns of methicillin-resistant Staphylococcus aureus strains causing community- and health care-associated infections in the northern region of Palestine. Am J Infect Control. 2013;41(3):195-8.

45. Al-Assil B, Mahfoud M, Hamzeh AR. Resistance trends and risk factors of extended spectrum beta-lactamases in Escherichia coli infections in Aleppo, Syria. Am J Infect Control. 2013;41(7):597-600.

46. Asaad AM, Zayed Al-Ayed MS, Ansar QM. Emergence of unusual nonfermenting gram-negative nosocomial pathogens in a Saudi hospital. Jpn J Infect Dis. 2013;66(6):507-11.

47. Aziz MA, El-Kholy I, Abdo A, Selim S. Influence of multi drug resistance gram negative bacteria in liver transplant recipient. Afr J Microbiol Res. 2013;7(41): 4857-61.

48. Dau AA, Tloba S, Daw MA. Characterization of wound infections among patients injured during the 2011 Libyan conflict. East Mediterr Health J. 2013;19(4):356-61.

49. Faris NS. Community-acquired urinary tract infection (etiology and bacterial susceptibility). J Biol Agricult Healthcare. 2013;3(3):36-41.

50. Nasereddin A, Shtayeh I, Ramlawi A, Salman N, Salem I, Abdeen Z. Streptococcus pneumoniae from Palestinian nasopharyngeal carriers: Serotype distribution and antimicrobial resistance. PLoS One. 2013;8 (12) (no pagination)(e82047)

51. Saadabi AM, Mohammed AH. Evaluation of antibiotic resistance for (methicillin-resistance) staphylococcus aureus. Int J Trop Med. 2013;8(5-6): 124-8.

52. See I, Lessa FC, Elata OA, Hafez S, Samy K, El-Kholy A, et al. Incidence and pathogen distribution of healthcare-associated infections in pilot hospitals in Egypt. Infect Control Hosp Epidemiol. 2013;34(12):1281-8.

53. Taha AB. Relationship and susceptibility profile of Staphylococcus aureus infection diabetic foot ulcers with Staphylococcus aureus nasal carriage. Foot. 2013;23(1):11-6.

54. Adwan K, Jarrar N, Abu-Hijleh A, Adwan G, Awwad E. Molecular characterization of Escherichia coli isolates from patients with urinary tract infections in Palestine. J Med Microbiol. 2014:63(PART 2):229-234.

55. Al-Akydy AG, Daoud H, Mulhem MM. Disc diffusion method versus pcr for meca gene in detection of oxacillin resistant staphylococcus Aureus in University Children's hospital in Damascus, Syria. Int J Pharm Pharm Sci. 2014;6(4):488-91.

56. Al-Zaidi JR, Al-Sulami AA. Detection of methicillin resistant Staphylococcus aureus (MRSA) in the surgical wards by chromogenic agar medium and PCR assay. Double Helix Res Int J Biomed Life Sci. 2014;5(3):381-97.

57. Alzoubi HM, Al-Shagahin HM, Al-Rawashdeh OSM, Alsbou MS, Kasasbeh BY, Aqel AA. Methicillin-resistant and methicillin-susceptible Staphylococcus aureus in allergic rhinitis patient and healthy individuals: prevalence, antibiotic susceptibility and effect on disease severity. Afr J Microbiol Res. 2014;8(37):3368-72.

58. Auda IG. Occurrence of CTX-M-I and CTX-M-III genes on plasmids of Shigella species isolated from cases of diarrhea in Baghdad. World J Pharmaceut Res. 2014:3(4):1273-80.

59. Buzayan MM, El-Garbulli FR. Detection of ESBL and AmpC beta -lactamases producing in uropathogen Escherichia coli isolates at Benghazi Center of Infectious Diseases and Immunity. Int J Curr Microbiol App Sci. 2014;3(2):145-53.

60. Dash N, Panigrahi D, Zarouni MA, Darwish D, Ghazawi A, Sonnevend A, et al. High incidence of New Delhi metallo-beta-lactamase-producing klebsiella pneumoniae isolates in Sharjah, United Arab Emirates. Microbial Drug Resist. 2014;20(1):52-6.

61. El-Din RAA, El-Bassat $\mathrm{H}$, El-Bedewy M, El-Mohamady $\mathrm{H}$. Prevalence of metallo- beta -lactamases producers among carbapenem-resistant Acinetobacter baumannii strains isolated from diabetic foot ulcers. Afr J Microbiol Res. 2014;8(15):1580-5.

62. Elfaky MA, Yassien MA, Attia AS, Mansy MS, Ashour MSE. Microbiological studies on resistance patterns of antimicrobial agents among gram negative respiratory tract pathogens. Afr J Microbiol Res. 2014;8(27):2583-91.

63. Es-Said I, Elfazazi H, Zouhdi M. In vitro activity of imipenem combination with colistin or rifampicin against clinical isolates of Acinetobacter baumannii and his antimicrobial susceptibility profil. Int J Innov Appl Stud. 2014;8(3):1252-7.

64. Es-Said I, Mahdoufi R, Yagoubi M, Zouhdi M. Isolation and antibiotic susceptibility of bacteria from otitis media infections in children in Rabat Morocco. J Biol Agricult Healthcare. 2014:4(28):153-9.

65. Fattouh M, El-Din AN, Abdelgalil W. Bacteriologic and immunologic profile of blood stream infected patients in intensive care unit of Sohag University hospital, Egypt. Int J Curr Microbiol App Sci. 2014;3(8):265-81. 
66. Harastani HH, Araj GF, Tokajian ST. Molecular characteristics of Staphylococcus aureus isolated from a major hospital in Lebanon. Int J Infect Dis. 2014;19:33-8.

67. Ibrahim IAJ, Al-Shwaikh RM, Ismaeil MI. Virulence and antimicrobial resistance of Escherichia Coli isolated from Tigris River and children diarrhea. Infect Drug Resist. 2014;7:317-22.

68. Nageeb W, Kamel M, Zakaria S, Metwally L. Phenotypic characterization of Acinetobacter baumannii isolates from intensive care units at a tertiary-care hospital in Egypt. East Mediterr Health J. 2014;20(3):203-11.

69. Rahim KAAA, Mohamed AMA. Prevalence of extended spectrum beta -lactamase-producing Klebsiella pneumoniae in clinical isolates. Jundishapur J Microbiol. 2014;7(11).

70. Salem-Bekhit MM. Phenotypic and genotypic characterization of nosocomial isolates of Staphylococcus aureus with reference to methicillin resistance. Trop J Pharm Res. 2014;13(8):1239-46.

71. Aamir MM, El-Wafa AWM, Ali AE, Hamouda HM, Mourad FE. Prevalence of multidrug resistant bacteria causing late-onset neonatal sepsis. Int J Curr Microbiol App Sci. 2015;4(5):172-90

72. Abdallah HM, Wintermans BB, Reuland EA, Koek A, al Naiemi N, Ammar AM, et al. Extended-Spectrum beta-Lactamase- and Carbapenemase-Producing Enterobacteriaceae Isolated from Egyptian Patients with Suspected Blood Stream Infection. PLoS One. 2015;10(5):e0128120.

73. Abdelmegeed ES, Barwa R, El-Galil KHA. Comparative study on prevalence and association of some virulence factors with extended spectrum betalactamases and AmpC producing Escherichia coli. Afr J Microbiol Res. 2015; 9(17):1165-74

74. Abou Shady HM, Bakr AE, Hashad ME, Alzohairy MA. Staphylococcus aureus nasal carriage among outpatients attending primary health care centers: a comparative study of two cities in Saudi Arabia and Egypt. Braz J Infect Dis. 2015;19(1):68-76.

75. Abujnah AA, Zorgani A, Sabri MAM, El-Mohammady H, Khalek RA, Ghenghesh KS. Multidrug resistance and extended-spectrum betalactamases genes among Escherichia coli from patients with urinary tract infections in Northwestern Libya. Libyan J Med. 2015;10(no pagination).

76. Al-Ahmadey ZZ. Prevalence of extended-spectrum beta-lactamase producing enterobacteriaece from various clinical isolates in Al-Ansar hospital, Medina, Saudi Arabia. J Pure Appl Microbiol. 2015;9(3):1927-32.

77. Alaklobi F, Aljobair F, Alrashod A, Alhababi R, Alshamrani M, Alamin W, et al. The prevalence of community-associated methicillin-resistant Staphylococcus aureus among outpatient children in a tertiary hospital: a prospective observational study in Riyadh, Saudi Arabia. Int J Pediatr Adolesc Med. 2015:2(3-4):136-40.

78. Al-Charrakh AH, Al-Hassnawi HH, Al-Khafaji JK. Molecular characteristics of community-associated methicillin-resistant Staphylococcus aureus (CA-MRSA) isolates from clinical specimens in Iraq. Br Microbiol Res J. 2015;5(3):227-36.

79. Al-Dahmoshi HOM, Al-Yassari AKSS, Al-Saad NFN, Al-Dabagh NN, Al-Khafaji NSK, Mahdi RK, et al. Occurrence of AmpC, MBL, CRE and ESBLs among diarrheagenic Escherichia coli recovered from infantile diarrhea, Iraq. J Pharmaceut Biomed Sci. 2015:5(3):189-95.

80. Alharbi $A E$, Alshami I. In vitro effects of tigecycline in combination with other antimicrobials against multidrug-resistant Acinetobacter baumannii isolates, J Pure Appl Microbiol. 2015;9(Special Edition 1):497-502.

81. Al-Humaidan OS, El-Kersh TA, Al-Akeel RA. Risk factors of nasal carriage of Staphylococcus aureus and methicillin-resistant Staphylococcus aureus among health care staff in a teaching hospital in Central Saudi Arabia. Saudi Med J. 2015;36(9):1084-90.

82. Aljanaby AAJ, Alhasani AHA. Prevalence of blaTEM and blaSHV genes in multidrug resistant Klebsiella pneumoniae isolated from hospital patients with burns infections in Al-Najaf governorate-Iraq. World J Pharmaceut Res. 2015;4(7):145-54.

83. Aljindan $\mathrm{R}$, Bukharie $\mathrm{H}$, Alomar $\mathrm{A}$, Abdalhamid B. Prevalence of digestive tract colonization of carbapenem-resistant Acinetobacter baumannii in hospitals in Saudi Arabia. J Med Microbiol. 2015;64(Pt 4):400-6.

84. Al-Khafaji NSK, Shareef HK, Al-Dahmoshi HOM. Analysis of beta-lactamases among multi drug resistant Klebsiella pneumoniae in Hilla city-Iraq. Res J Pharm, Biol Chem Sci. 2015;6(4):903-7.

85. Alsultan AA. Clonal diversity of Acinetobacter baumannii mediated by carbapenem resistance in Saudi Arabian hospitals. Int J Curr Microbiol App Sci. 2015;4(5):525-36

86. Barguigua A, Zerouali K, Katfy K, El Otmani F, Timinouni M, Elmdaghri N. Occurrence of OXA-48 and NDM-1 carbapenemase-producing Klebsiella pneumoniae in a Moroccan university hospital in Casablanca, Morocco. Infect Genet Evol. 2015;31:142-8.

87. Bassyouni RH, Gaber SN, Wegdan AA. Fecal carriage of extended-spectrum beta -lactamase- and AmpC-producing Escherichia coli among healthcare workers. J Infect Dev Countries. 2015;9(3):304-8.

88. Batarseh A, Al-Sarhan A, Maayteh M, Al-Khatirei S, Alarmouti M. Antibiogram of multidrug resistant Acinetobacter baumannii isolated from clinical specimens at king Hussein medical Centre, Jordan: a retrospective analysis. East Mediterr Health J. 2015;21(11):828-34.

89. Eida M, Nasser M, El-Maraghy N, Azab K. Pattern of hospital-acquired pneumonia in intensive care unit of Suez Canal University hospital. Egypt J Chest Dis Tuberc. 2015;64(3):625-31.

90. Elabd FM, Al-Ayed MSZ, Asaad AM, Alsareii SA, Qureshi MA, Musa HAA. Molecular characterization of oxacillinases among carbapenem-resistant Acinetobacter baumannii nosocomial isolates in a Saudi hospital. J Infect Public Health. 2015;8(3):242-7.

91. El-Kazzaz SS, El-Khier NTA. AmpC and metallo beta-lactamases producing gram negative bacteria in patients with hematological malignancy. Afr J Microbiol Res. 2015;9(18):1247-54.

92. Elkersh T, Marie MA, Al-Sheikh YA, Ahmad A, Al-Agamy MH. Prevalence of fecal carriage of extended-spectrum- and metallo- beta -lactamaseproducing gram-negative bacteria among neonates born in a hospital setting in Central Saudi Arabia. Ann Saudi Med. 2015;35(3):240-7.

93. El-Nawawy AA, Hafez SF, Meheissen MA, Shahtout NMA, Mohammed EE. Nasopharyngeal carriage, capsular and molecular serotyping and antimicrobial susceptibility of Streptococcus pneumoniae among asymptomatic healthy children in Egypt. J Trop Pediatr. 2015;61(6): 455-63.

94. El-Sokkary MMA, Abdelmegeed ES. Antibacterial resistance pattern among Escherichia coli strains isolated from Mansoura hospitals in Egypt with a special reference to quinolones. Afr J Microbiol Res. 2015;9(9):662-70.

95. Hussein NR, Basharat Z, Muhammed AH, Al-Dabbagh SA. Comparative evaluation of MRSA nasal colonization epidemiology in the Urban and Rural Secondary School Community of Kurdistan, Iraq. PLoS One. 2015;10(5): e0124920.

96. Kilkal I, Al-Ani ZNH, Abbas HH. Establishment of horizontal transformation of VanA gene from another bacterial species to Staphylococcus aureus by curing. Int J Curr Microbiol App Sci. 2015;4(8):148-56.

97. Lopes BS, Al-Agamy MH, Ismail MA, Shibl AM, Al-Qahtani AA, Al-Ahdal MN, et al. The transferability of blaOXA-23 gene in multidrug-resistant Acinetobacter baumannii isolates from Saudi Arabia and Egypt. Int J Med Microbiol. 2015;305(6):581-8.

98. Mahmoud MS, Esmail MAM, Khairy RMM, Mazher OS. Detection of multidrug resistant non-typhoid Salmonella isolates in cases of gastroenteritis in Egypt. Br Microbiol Res J. 2015;6(3):167-74.

99. Mohamed MS, El-Mokhtar MA, Hassan AT. Bacterial profile and antibiotic susceptibility patterns of acute exacerbation of chronic obstructive pulmonary disease in Assiut University hospitals, upper Egypt; a one-year prospective study. Br Microbiol Res J. 2015;7(6):288-305.

100. Moutachakkir M, Chinbo M, Elkhoudri N, Soraa N. Antibiotic resistance of uropathogenic enterobacteriaceae in pediatric wards at the University Hospital of Marrakech. [French]. J Pediatr Pueric. 2015;28(1):16-22.

101. Rafei $R$, Pailhories $H$, Hamze M, Eveillard M, Mallat H, Dabboussi F, et al. Molecular epidemiology of Acinetobacter baumannii in different hospitals in Tripoli, Lebanon using Bla(OXA-51-like) sequence based typing. BMC Microbiol. 2015;15:103

102. Zakai SA. Prevalence of methicillin-resistant staphylococcus aureus nasal colonization among medical students in Jeddah, Saudi Arabia. Saudi Med J. 2015;36(7):807-12.

103. Zaki MES, Elewa A. Molecular study of Staphylococcus species isolated from children with sepsis in pediatric intensive care: one Egyptian center study. Int J Curr Microbiol App Sci. 2015;4(6):800-10.

104. Zorgani A, Abofayed A, Glia A, Hanish AAS. Prevalence of device-associated nosocomial infections caused by gram-negative bacteria in a trauma intensive care unit in Libya. Oman Med J. 2015;30(4):270-5.

105. Abdel-Moaty MM, Mohamed WS, Abdel-All SM, El-Hendawy HH. Prevalence and molecular epidemiology of extended spectrum beta -lactamase producing Escherichia coli from hospital and community settings in Egypt. J Appl Pharmaceut Sci. 2016;6(1):42-7.

106. Al Atrouni A, Hamze M, Jisr T, Lemarie C, Eveillard M, Joly-Guillou ML, et al. Wide spread of OXA-23-producing carbapenem-resistant Acinetobacter 
baumannii belonging to clonal complex II in different hospitals in Lebanon. Int J Infect Dis. 2016;52:29-36.

107. Al Yousef SA, Younis S, Farrag E, Moussa H, Bayoumi FS, Ali AM. Clinical and laboratory profile of urinary tract infections associated with extended Spectrum beta-lactamase producing Escherichia coli and Klebsiella pneumoniae. Ann Clin Lab Sci. 2016;46(4):393-400.

108. Al-Bshabshe A, Joseph MRP, Al-Hussein A, Waleed H, Hamid ME. Multidrug resistance Acinetobacter species at the intensive care unit, Aseer central hospital, Saudi Arabia: a one year analysis. Asian Pac J Trop Med. 2016;9(9): $881-5$.

109. Al-Dahhan HAA, Muhana ES, Al-Fatlawy AAH. Antibiotic resistance of Escherichia coli isolated from urinary tract infections patients in three Iraqi governorates during 2011-2012: a comparative study. World J Pharm Res. 2016;5(7):246-57.

110. Al-Harmoosh RA, Jarallah EM, Al-Shamari AM. Coexistence of the blaIMP and blaSIM genes in clinical isolates of acinetobacter baumanniiin babylon hospitals-Iraq. Int J PharmTech Re. 2016;9(7):257-64.

111. Alhussaini MS. Methicillin-resistant Staphylococcus aureus nasal carriage among patients admitted at Shaqra general Hospital in Saudi Arabia. Pak J Biol Sci. 2016;19(5):233-8.

112. Aljanaby AAJ, Alhasani AHA. Virulence factors and antibiotic susceptibility patterns of multidrug resistance Klebsiella pneumoniae isolated from different clinical infections. Afr J Microbiol Res. 2016;10(22):829-43.

113. Almasri M, Hasan NA, Sabbah N. Macrolide and lincosamide resistance in staphylococcal clinical isolates in Nablus, Palestine Turkish. J Med Sci. 2016; 46(4):1064-70.

114. Al-Mayahie SMG, Al-Kuriashy JJH. Distribution of ESBLs among Escherichia coli isolates from outpatients with recurrent UTIs and their antimicrobial resistance. J Infect Dev Countries. 2016;10(6):575-83.

115. Al-Otaibi FE, Bukhari EE, Mona B, Alrabiaa AA. Prevalence and risk factors of gram-negative bacilli causing blood stream infection in patients with malignancy. Saudi Med J. 2016;37(9):979-84.

116. Al-Yousef SA. Surveillance of antibiotic-resistant bacteria in King Khalid Hospital, Hafr Al-Batin, Saudi Arabia, during 2013. Jundishapur J Microbiol 2016;9(9).

117. Alzahrani AK, Farag MM, Abbadi SH, Hassan MM, Gaber A, Abdel-Moneim AS. Antibiotic resistance profile and random amplification typing of betalactamase-producing Enterobacteriaceae from the local area of Al-Taif and nearby cities in Saudi Arabia. Asian Biomed. 2016;10(3):219-28.

118. Aziz RAR, Al-Jubori SS. Genetic elements responsible for extreme drug resistance (XDR) in Klebsiella pnumoniae var pnumoniae isolated from clinical samples of Iraqi patients. World J Pharm Res. 2016;5(5):1-23.

119. Badran EF, Din RAQ, Shehabi AA. Low intestinal colonization of Escherichia coli clone ST131 producing CTX-M-15 in Jordanian infants. J Med Microbiol. 2016;65(2):137-41.

120. Bahy RH, Hamouda HM, Shahat AS, Yassin AS, Amin MA. Emergence of neoteric serotypes among multidrug resistant strains of Streptococcus pneumoniae prevalent in Egypt. Jundishapur Journal of Microbiology. 2016;9(4).

121. Barakat GI, Nabil YM. Correlation of mupirocin resistance with biofilm production in methicillin-resistant Staphylococcus aureus from surgical site infections in a tertiary Centre, Egypt. J Glob Antimicrobial Resistance. 2016:4:16-20.

122. Bin Mohanna MA, Bahannan AA. Bacterial profile and Antibiogram of otitis media among children in Yemen. J Ayub Med Coll Abbottabad. 2016;28(3):480-3.

123. Chamoun K, Farah M, Araj G, Daoud Z, Moghnieh R, Salameh P, et al. Surveillance of antimicrobial resistance in Lebanese hospitals: retrospective nationwide compiled data. Int J Infect Dis. 2016;46:64-70.

124. Dahdouh E, Hajjar M, Suarez M, Daoud Z. Acinetobacter baumannii isolated from Lebanese patients: phenotypes and genotypes of resistance, Clonality, and determinants of pathogenicity. Front. 2016;6:163.

125. Elbargisy RM, Rizk DE, Abdel-Rhman SH. Toxin gene profile and antibiotic resistance of Staphylococcus aureus isolated from clinical and food samples in Egypt. Afr J Microbiol Res. 2016;10(13):428-37.

126. Ghaima KK, Saadedin SMK, Jassim KA. Prevalence of BlaOXA like carbapenemase genes in multidrug resistant Acinetobacter baumannii isolated from burns and wounds in Baghdad hospitals. Res J Pharm, Biol Chem Sci. 2016;7(3):1247-54.

127. Jamsheer A, Rafay AM, Daoud Z, Morrissey I, Torumkuney D. Results from the Survey of Antibiotic Resistance (SOAR) 2011-13 in the Gulf States. J Antimicrobial Chemother. 2016;71(Supplement 1):i45-61.
128. Omran L, Askar E. Antibiotic sensitivity patterns of the most common bacteria isolated from al-mouwasat university hospitalin 2015, Syria. Int J PharmTech Res. 2016;9(1):113-9.

129. Saleem AJ, Nasser NE, Ali MR. Prevalence of genes encoding enterotoxins and exfoliative toxins among methicillin resistant Staphylococcus aureus clinical isolates in Iraq. World J Pharm Res. 2016;5(7):208-16.

130. Sewify M, Nair S, Warsame S, Murad M, Alhubail A, Behbehani K, et al. Prevalence of Urinary Tract Infection and Antimicrobial Susceptibility among Diabetic Patients with Controlled and Uncontrolled Glycemia in Kuwait. J Diab Res. 2016;2016(Article ID 6573215).

131. Sharaf HE, Gerges MA. Nosocomial imipenem-resistant Acinetobacter Baumannii infections in intensive care units: incidence and risk factors assessment. Afr J Clin Exp Microbiol. 2016;17(4):243-9.

132. Swedan SF, Hayajneh WA, Bshara GN. Genotyping and serotyping of macrolide and multidrug resistant Streptococcus pneumoniae isolated from carrier children. Indian J Med Microbiol. 2016;34(2):159-65.

133. Abdelhamid S. Time to positivity and antibiotic sensitivity of neonatal blood cultures. J Global Infect Dis. 2017;9(3):102-7.

134. Abdelkader MM, Aboshanab KM, El-Ashry MA, Aboulwafa MM. Prevalence of MDR pathogens of bacterial meningitis in Egypt and new synergistic antibiotic combinations. PLoS One. 2017;12(2):e0171349.

135. Alam MZ, Alam Q, Jiman-Fatani AA, Shukri HA, Haque A. A surveillance study on the prevalence and antimicrobial resistance pattern among different groups of bacteria isolated from Western province of Saudi Arabia. Biomed Res (India). 2017;28(2):898-906.

136. Alavudeen SS, Vigneshwaran E, Asiri SAA, Alahmari MHA, Mohammed MA, Algahtani T, et al. Distribution of multi-resistant bacterial isolates from clinical specimens in a hospital environment of Kingdom of Saudi Arabia. J Young Pharm. 2017;9(3):347-51.

137. Aljanaby AAJ, Medhat AR. Prevalence of some antimicrobials resistance associated-genes in Salmonella typhi isolated from patients infected with typhoid fever. J Biol Sci. 2017;17(4):171-84.

138. Alkasaby NM, El Sayed Zaki M. Molecular Study of Acinetobacter baumannii Isolates for Metallo-beta-Lactamases and Extended-Spectrum-betaLactamases Genes in Intensive Care Unit, Mansoura University Hospital, Egypt. Int J Microbiol. 2017:2017:3925868.

139. Alkasaby NM, El-Khier NTA. Phenotypic and genotypic detection of macrolide-lincosamide-streptogramin B resistance among clinical isolates of Staphylococcus aureus from Mansoura University children hospital, Egypt African. J Microbiol Res. 2017;11(12):488-94.

140. Aziz RAR, Al-Jubori SS. Molecular analysis of genetic elements responsible for XDR in highly successful pathogen Acinetobacter baumannii isolated from clinical samples of Iraqi patients. J Glob Pharma Technol. 2017;9(4):26-39.

141. Baaity Z, Almahmoud I, Khamis A. Prevalence of extended spectrum beta lactamases (ESBL) in E. coli at Al-assad teaching hospital. Res J Pharm Technol. 2017;10(7):2433-6.

142. Badawi AE, Moemen D, El-Tantawy NL. Epidemiological, clinical and laboratory findings of infectious keratitis at Mansoura ophthalmic center, Egypt. Int J Ophthalmol. 2017;10(1):61-7.

143. Benaicha H, Barrijal S, Ezzakkioui F, Elmalki F. Prevalence of PMQR genes in $E$ coli and Klebsiella spp isolated from North-West of Morocco. J Glob Antimicrob Resist. 2017;10:321-5.

144. El Aila NA, Al Laham NA, Ayesh BM. Nasal carriage of methicillin resistant Staphylococcus aureus among health care workers at Al Shifa hospital in Gaza strip. BMC Infect Dis. 2017;17(1):28.

145. El-Badawy MF, Tawakol WM, El-Far SW, Maghrabi IA, Al-Ghamdi SA, Mansy MS, et al. Molecular identification of aminoglycoside-modifying enzymes and plasmid-mediated quinolone resistance genes among Klebsiella pneumoniae clinical isolates recovered from Egyptian patients. Int J Microbiol. 2017;8050432(43).

146. El-Gamasy MA, Mehrez MM, Fakhreldin AR, Alenany AFE. Microbiological profile of urinary tract infection in pediatric age, Egyptian two centers experience. Int J Drug Res Technol. 2017;7(5):223-33.

147. Elnasasra A, Alnsasra H, Smolyakov R, Riesenberg K, Nesher L. Ethnic diversity and increasing resistance patterns of hospitalized communityacquired urinary tract infections in southern Israel: a prospective study. Israel Med Assoc J. 2017;19(9):538-42.

148. Elshabrawy WO, Zaki ME, Kamel MF. Genetic and phenotypic study of methicillin-resistant Staphylococcus aureus among patients and health care workers in Mansoura University hospital, Egypt Iranian. J Microbiol. 2017;9(2):82-8. 
149. Fadlallah SM, Shehab M, Cheaito K, Saleh M, Ghosn N, Ammar W, et al. Molecular epidemiology and antimicrobial resistance of Salmonella species from clinical specimens and food items in Lebanon. J Infect Dev Countries. 2017;11(1):19-27.

150. Hashem AA, Abd El Fadeal NM, Shehata AS. In vitro activities of vancomycin and linezolid against biofilm-producing methicillin-resistant staphylococci species isolated from catheter-related bloodstream infections from an Egyptian tertiary hospital. J Med Microbiol. 2017;66(6):744-52.

151. Hussein NH. Genotypic detection of Carbapenem-Resistant Escherichia coli producing NDM-1 gene for the first time in Baghdad/Iraq. J Glob Pharma Technol. 2017:9(9PartB):106-111.

152. Ktari S, Jmal I, Mroua M, Maalej S, Ben Ayed NE, Mnif B, et al. Serotype distribution and antibiotic susceptibility of Streptococcus pneumoniae strains in the south of Tunisia: a five-year study (2012-2016) of pediatric and adult populations. Int J Infect Dis. 2017:65:110-5.

153. Lachhab Z, Frikh M, Maleb A, Kasouati J, Doghmi N, Ben Lahlou Y, et al. Bacteraemia in Intensive Care Unit: Clinical, Bacteriological, and Prognostic Prospective Study. Canadian Journal of Infectious Diseases and Medical Microbiology. 2017;2017 (Article ID 4082938).

154. Mashwal FA, El-Safi SH, George SK, Adam AA, Jebakumar AZ. Incidence and molecular characterization of the extended spectrum beta lactamaseproducing Escherichia coli isolated from urinary tract infections in eastern Saudi Arabia. Saudi Med J. 2017;38(8):811-5.

155. Natoubi S, Barguigua A, Baghdad N, Nayme K, Timinouni M, Hilali A, et al. Occurrence of carbapenemases and extended-spectrum beta-lactamases in uropathogenic Enterobacteriaceae isolated from a community setting, Settat, Morocco. Asian J Pharm Clin Res. 2017;10(1):211-5.

156. Saadi AT, Garjees NA, Rasool AH. Antibiogram profile of septic meningitis among children in Duhok, Iraq Saudi. Med J. 2017;38(5):517-20.

157. Soudeiha MAH, Dahdouh EA, Azar E, Sarkis DK, Daoud Z. In vitro Evaluation of the Colistin-Carbapenem Combination in Clinical Isolates of A. baumannii Using the Checkerboard, Etest, and Time-Kill Curve Techniques. Front. 2017;7:209.

158. Taha BM. Molecular detection of Per-1 type extended Spectrum BLactamase among clinical isolates of Klebsiella pneumoniae in Baghdad Hospitals. J Glob Pharma Technol. 2017;9(9PartB):103-106.

159. Zorgani A, Almagatef A, Sufya N, Bashein A, Tubbal A. Detection of CTX-M15 among uropathogenic Escherichia coli isolated from five major hospitals in Tripoli, Libya Oman. Med J. 2017;32(4):322-7.

160. Zorgani A, Daw H, Sufya N, Bashein A, Elahmer O, Chouchani C. Cooccurrence of plasmid-mediated AmpC beta-lactamase activity among Klebsiella pneumoniae and Escherichia Coli. Open Microbiol J. 2017;11: 195-202.

161. Älgå A, Wong S, Shoaib M, Lundgren K, Giske CG, von Schreeb J, et al. Infection with high proportion of multidrug-resistant bacteria in conflictrelated injuries is associated with poor outcomes and excess resource consumption: a cohort study of Syrian patients treated in Jordan. BMC Infect Dis. 2018;18(1):233

162. Aljanaby AAJ, Tuwaij NSS, Al-Khilkhali HJB. Antimicrobial susceptibility patterns of Klebsiella pneumoniae isolated from older smokers and nonsmokers of inpatients in intensive care unit infected with chronic pneumonia in AL-Najaf hospital, Iraq. J Pharm Sci Res. 2018;10(5):1093-7.

163. Al-Tamimi M, Himsawi N, Abu-Raideh J, Jazar DA, Al-Jawaldeh H, Mahmoud $\mathrm{SAH}$, et al. Nasal colonization by methicillin-sensitive and methicillinresistant staphylococcus aureus among medical students. J Infect Dev Countries. 2018;12(5):326-35.

164. Balkhi B, Mansy W, Alghadeer S, Alnuaim A, Alshehri A, Somily A. Antimicrobial susceptibility of microorganisms causing urinary tract infections in Saudi Arabia. J Infect Dev Countries. 2018;12(4):220-7.

165. Dash RN, Albataineh MT, Alhourani N, Khoudeir AM, Ghanim M, Wasim M, et al. Community-acquired urinary tract infections due to extendedspectrum beta -lactamase-producing organisms in United Arab Emirates. Travel Med Infect Dis. 2018;22:46-50.

166. Gawad WE, Helmy OM, Tawakkol WM, Hashem AM. Antimicrobial resistance, biofilm formation, and phylogenetic grouping of uropathogenic Escherichia coli isolates in Egypt: The role of efflux pump-mediated resistance. Jundishapur J Microbiol. 2018;11(2):e14444.

167. Hajjar Soudeiha M, Dahdouh E, Daoud Z, Sarkis DK. Phenotypic and genotypic detection of beta-lactamases in Acinetobacter spp. isolates recovered from Lebanese patients over a 1-year period. J Glob Antimicrob Resist. 2018;12:107-12.
168. Hassan EA, Elsherbiny NM, Abd El-Rehim AS, Soliman AMA, Ahmed AO. Health care-associated infections in pre-transplant liver intensive care unit: perspectives and challenges. J Infect Public Health. 2018;11(3):398-404.

169. Nairoukh YR, Mahafzah AM, Irshaid A, Shehabi AA. Molecular characterization of multidrug resistant uropathogenic e. coli isolates from Jordanian patients. Open Microbiol J. 2018;12:1-7.

170. Senok AC, Somily A, Raji M, Garaween G, Kabil M, Shibl A, et al. Genotyping of staphylococcus aureus associated with nasal colonization among healthcare workers using DNA microarray. J Infect Dev Countries. 2018;12(5):321-5.

171. Tektook KN. Study the virulence factors and patterns of antibiotics resistance in acinetobacter baumannii isolated from hospitalized patients in Baghdad City. Pak J Biotechnol. 2018;15(1):19-23.

172. Tohamy ST, Aboshanab KM, El-Mahallawy HA, El-Ansary MR, Afifi SS. Prevalence of multidrug-resistant gram-negative pathogens isolated from febrile neutropenic cancer patients with bloodstream infections in Egypt and new synergistic antibiotic combinations. Infect Drug Resistance. 2018; $11: 791-803$

173. UNHCR. Figures at a glance 2018 [updated 2018. Available from: http:// www.unhcr.org/figures-at-a-glance.html.

174. The World Bank. Refugee population by country or territory of asylum 2018 [updated 2018. Available from: https://data.worldbank.org/ indicator/SM.POP.REFG.

175. de Kraker MEA, Stewardson AJ, Harbarth S. Will 10 million people die a year due to antimicrobial resistance by 2050? PLoS Med. 2016;13(11):e1002184.

176. Naylor NR, Atun R, Zhu N, Kulasabanathan K, Silva S, Chatterjee A, et al. Estimating the burden of antimicrobial resistance: a systematic literature review. Antimicrob Resist Infect Control. 2018;7:58.

177. Knight GM, Costelloe C, Murray KA, Robotham JV, Atun R, Holmes AH. Addressing the unknowns of antimicrobial resistance: quantifying and mapping the drivers of burden. Clin Infect Dis. 2018;66(4):612-6.

178. Holmes AH, Moore LS, Sundsfjord A, Steinbakk M, Regmi S, Karkey A, et al. Understanding the mechanisms and drivers of antimicrobial resistance. Lancet (London, England). 2016;387(10014):176-87.

179. The World Bank. World Bank Country and Lending Groups 2017 [Available from: https://datahelpdesk.worldbank.org/knowledgebase/articles/906519.

180. Alhomoud F, Aljamea Z, Almahasnah R, Alkhalifah K, Basalelah L, Alhomoud FK. Self-medication and self-prescription with antibiotics in the Middle East-do they really happen? A systematic review of the prevalence, possible reasons, and outcomes. Int J Infect Dis. 2017;57:3-12.

181. Nasr Z, Paravattil B, Wilby KJ. The impact of antimicrobial stewardship strategies on antibiotic appropriateness and prescribing behaviours in selected countries in the Middle East: a systematic review. East Mediterr Health J. 2017;23(6):430-40.

182. Abbara A, Rawson TM, Karah N, El-Amin W, Hatcher J, Tajaldin B, et al. Antimicrobial resistance in the context of the Syrian conflict: drivers before and after the onset of conflict and key recommendations. Int J Infect Dis. 2018;73:1-6.

183. Abbara A, Rawson TM, Karah N, El-Amin W, Hatcher J, Tajaldin B, et al. Part 1: antimicrobial resistance in the context of the Syrian conflict: a summary and appraisal of existing evidence. International journal of infectious diseases : IJID : official publication of the International Society for Infectious Diseases 2018.

184. WHO. GLASS Country Profiles 2016 [Available from: http://apps.who.int/gho/ tableau-public/tpc-frame.jsp?id=2004.

185. Public Health England. English Surveillance Program for Antimicrobial Utilization and Resistance (ESPAUR): Report 2017. October 2017.

186. Symvoulakis EK, Anyfantakis D, Markaki A. Overuse of antibiotics in primary health care: A practitioner- or patient-induced problem? JAMA Intern Med. 2015:175(5):863.

187. Habibzadeh F. Use and misuse of antibiotics in the Middle East. Lancet (London, England). 2013;382:1.

188. Khalifeh MM, Moore ND, Salameh PR. Self-medication misuse in the Middle East: a systematic literature review. Pharmacol Res Perspect. 2017:5(4):e00323.

189. ECDC. Annual report of the European Antimicrobial Resistance Surveillance Network (EARS-Net) 2016. 2017.

190. Girmenia C, Serrao A, Canichella M. Epidemiology of Carbapenem resistant Klebsiella pneumoniae infections in Mediterranean countries. Med J Hematol Infect Dis. 2016:8(1):e2016032

191. Zigmond J, Pecan L, Hajek P, Raghubir N, Omrani AS. MRSA infection and colonization rates in Africa and Middle East: A systematic review \& metaanalysis. Int J Infect Dis. 2014;1:391. 
192. Falagas ME, Karageorgopoulos DE, Leptidis J, Korbila IP. MRSA in Africa: filling the global map of antimicrobial resistance. PLoS One. 2013;8(7): e68024.

193. O'Shea MK. Acinetobacter in modern warfare. Int J Antimicrob Agents. 2012; 39(5):363-75.

194. Rafei R, Dabboussi F, Hamze M, Eveillard M, Lemarie C, Mallat H, et al. First report of blaNDM-1-producing Acinetobacter baumannii isolated in Lebanon from civilians wounded during the Syrian war. Int J Infect Dis. 2014;21:21-3.

195. Tokajian S, Eisen JA, Jospin G, Hamze M, Rafei R, Salloum T, et al. Draft Genome Sequences of Acinetobacter baumannii Strains Harboring the blaNDM-1 Gene Isolated in Lebanon from Civilians Wounded during the Syrian Civil War. Genome announcements. 2016;4(1).

196. El-Moujaber G, Osman M, Rafei R, Dabboussi F, Hamze M. Molecular mechanisms and epidemiology of resistance in Streptococcus pneumoniae in the Middle East region. J Med Microbiol. 2017;66(7):847-58.

197. Abu-Raddad LJ, Ghanem KG, Feizzadeh A, Setayesh H, Calleja JMG, Riedner G. HIV and other sexually transmitted infection research in the Middle East and North Africa: promising progress? Sex Transmitted Infect. 2013;89(Suppl 3):iii -4.

198. Kimbrough W, Saliba V, Dahab M, Haskew C, Checchi F. The burden of tuberculosis in crisis-affected populations: a systematic review. Lancet Infect Dis. 2012;12(12):950-65.

199. Hunter JP, Saratzis A, Sutton AJ, Boucher RH, Sayers RD, Bown MJ. In metaanalysis of proportion studies, funnel plots were found to be an inaccurate method of assessing publication bias. J Clin Epidemiol. 2014;67(8):897-903.

200. Al Bayssari C, Diene SM, Loucif L, Gupta SK, Dabboussi F, Mallat H, et al. Emergence of VIM-2 and IMP-15 carbapenemases and inactivation of oprD gene in carbapenem-resistant Pseudomonas aeruginosa clinical isolates from Lebanon. Antimicrob Agents Chemother. 2014;58(8):4966-70.

201. Mahfoud M, Al Najjar M, Hamzeh AR. Multidrug resistance in Pseudomonas aeruginosa isolated from nosocomial respiratory and urinary infections in Aleppo, Syria. J Infect Dev Countries. 2015;9(2):210-3.

202. Zahedi Bialvaei A, Samadi Kafil H, Ebrahimzadeh Leylabadlo H, Asgharzadeh M, Aghazadeh M. Dissemination of carbapenemases producing gram negative bacteria in the Middle East. Iran J Microbiol. 2015;7(5):226-46.

203. Ceyhan M, Anis S, Htun-Myint L, Pawinski R, Soriano-Gabarró M, Vyse A. Meningococcal disease in the Middle East and North Africa: an important public health consideration that requires further attention. Int I Infect Dis. 2012;16(8):e574-e82.

204. Mackay IM, Arden KE. MERS coronavirus: diagnostics, epidemiology and transmission. Virol J. 2015;12:222.

\section{Publisher's Note}

Springer Nature remains neutral with regard to jurisdictional claims in published maps and institutional affiliations.

Ready to submit your research? Choose BMC and benefit from:

- fast, convenient online submission

- thorough peer review by experienced researchers in your field

- rapid publication on acceptance

- support for research data, including large and complex data types

- gold Open Access which fosters wider collaboration and increased citations

- maximum visibility for your research: over $100 \mathrm{M}$ website views per year

At $\mathrm{BMC}$, research is always in progress.

Learn more biomedcentral.com/submissions 